\title{
Prediction of Arctic Temperature and Sea Ice Using a High-Resolution Coupled Model
}

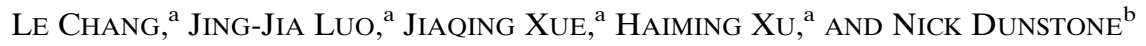 \\ ${ }^{\text {a } I n s t i t u t e ~ f o r ~ C l i m a t e ~ a n d ~ A p p l i c a t i o n ~ R e s e a r c h / K e y ~ L a b o r a t o r y ~ o f ~ M e t e o r o l o g i c a l ~ D i s a s t e r, ~}$ \\ Ministry of Education/Collaborative Innovation Center on Forecast and Evaluation of Meteorological Disasters, \\ Nanjing University of Information Science and Technology, Nanjing, China \\ ${ }^{\mathrm{b}}$ Met Office, Exeter, United Kingdom
}

(Manuscript received 1 April 2020, in final form 15 January 2021)

\begin{abstract}
Under global warming, surface air temperature has risen rapidly and sea ice has decreased markedly in the Arctic. These drastic climate changes have brought about various severe impacts on the vulnerable environment and ecosystem there. Thus, accurate prediction of Arctic climate becomes more important than before. Here we examine the seasonal to interannual predictive skills of 2-m air temperature (2-m $T)$ and sea ice cover (SIC) over the Arctic region (70 $90^{\circ} \mathrm{N}$ ) during 1980-2014 with a high-resolution global coupled model called the Met Office Decadal Prediction System, version 3 (DePreSys3). The model captures well both the climatology and interannual variability of the Arctic 2-m $T$ and SIC. Moreover, the anomaly correlation coefficient of Arctic-averaged 2-m $T$ and SIC shows statistically significant skills at lead times up to 16 months. This is mainly due to the contribution of strong decadal trends. In addition, it is found that the peak warming trend of Arctic 2-m $T$ lags the maximum decrease trend of SIC by 1 month, in association with the heat flux forcing from the ocean surface to lower atmosphere. While the predictive skill is generally much lower for the detrended variations, we find a close relationship between the tropical Pacific El Niño-Southern Oscillation and the Arctic detrended 2-m $T$ anomalies. This indicates potential seasonal to interannual predictability of the Arctic natural variations.
\end{abstract}

KEYWORDS: Ice loss/growth; Climate prediction; Ensembles; Hindcasts; Seasonal forecasting

\section{Introduction}

It has been widely recognized that the persistent global warming in the past decades to century has made profound impacts on our environment and socioeconomic activities (IPCC 2013). In particular, associated with global warming, surface air temperature over the Arctic has increased almost 2 times as fast as that over the Northern Hemisphere or the whole globe during the past 60 years (Serreze and Francis 2006; IPCC 2007; Serreze and Barry 2011). For instance, the Arctic Climate Impact Assessment reported that wintertime surface air temperature over the Arctic has risen $3^{\circ}-4^{\circ} \mathrm{C}$ over the past 50 years (Chapman and Walsh 2007). This phenomenon is called the "Arctic amplification," which is especially significant in boreal autumn and winter and is now recognized as an inherent feature of the global climate change (Serreze and Barry 2011). Many previous studies demonstrated that albedo positive feedback associated with the loss of snow and sea ice is one of the important driving mechanisms of the amplified surface warming in the Arctic (Serreze et al. 2009; Pithan and Mauritsen 2014; Johannessen et al. 2016; Goosse et al. 2018). And there has been a consensus that sea ice variation is one of the most crucial indicators of the Arctic climate change (Döscher et al. 2014). The rapid decline of sea ice cover over the past few decades has been considered as a precursor signal of global climate change (Walsh 1983; Notz and Marotzke 2012). The increase of Siberian snowfall in autumn/ winter (Deser et al. 2010), polar stratospheric cooling (Screen et al. 2013), and a weakening of the midlatitude jet (Francis et al. 2009) are suggested to be linked to the decrease of Arctic sea ice.

Corresponding author: Jing-Jia Luo, jjluo@nuist.edu.cn
Many previous studies pointed out that the Arctic climate plays an important role in global energy balance and atmospheric and oceanic circulations (e.g., Barber et al. 2009). The sea level rise, the destruction of terrestrial and marine ecosystems as well as the threat of indigenous people's lives caused by the rapid Arctic warming are gradually becoming serious issues. Meanwhile, more often ice-free Arctic Ocean in boreal summer and autumn is expected to have widespread effects (Francis and Vavrus 2012). For example, increasing marine accessibility to Arctic waters can impact commercial shipping, fishing, and oil drilling (Eicken 2013; Sigmond et al. 2013). The atmospheric circulation changes associated with the sea ice loss further influence precipitation, seasonal variation of temperatures, storm tracks, and low-level winds in midlatitudes (Budikova 2009; Honda et al. 2009; Francis et al. 2009; Overland and Wang 2010; Petoukhov and Semenov 2010; Deser et al. 2010; Jaiser et al. 2012). Therefore, accurate predictions of Arctic climate changes on seasonal to interannual time scales are extremely important for a broad group of stakeholders.

Several early studies in the 1980s (e.g., Walsh 1980; Johnson et al. 1985) attempted to perform seasonal prediction of the Arctic sea ice based on statistical methods. Drobot and Maslanik (2002) found that, using the sea ice concentration in winter and spring, ice conditions in the Beaufort Sea in late summer was predictable. With statistical models being continuously improved, the prediction of Arctic sea ice extent (SIE) in September exhibited good skill based on the preceding ocean variables and sea ice (Lindsay et al. 2008). Recently, it was found that the prediction skill of the Arctic sea ice by dynamical models is comparable to, or even higher than, that of statistical models (Day et al. 2014). Wang et al. (2013) performed a retrospective prediction experiment of the Arctic SIE using the Climate Forecast System, version 2 (CFSv2), and found the greatest skill at a lead time of 3 months in predicting 
the SIE in winter and spring (December-March). Using 5-monthlong predictions that are based on the Centre National de Recherches Météorologiques Coupled Model, version 5.1 (CNRM-CM5.1), Chevallier et al. (2013) showed that the forecast system can predict the pan-Arctic SIE in September and March out to 5-months lead, with correlations of 0.72 and 0.74 for each target month.

Palmer et al. (2004) demonstrated that combining multimodel and ensemble techniques can improve both deterministic and probabilistic seasonal predictions relative to single-model forecasts, mainly because of error compensation and its greater consistency and reliability (Hagedorn et al. 2016). Using two atmosphere-ocean-sea ice coupled climate prediction systems, called the CFSv2 and the Canadian Seasonal to Interannual Prediction System (CanSIPS), respectively, Merryfield et al. (2013) found that the combination of the two forecast systems outperformed the single system in predicting the winter Arctic sea ice area (SIA) up to a lead time of 7 months (Guemas et al. 2016). Harnos et al. (2019) used five models of the North American Multimodel Ensemble (NMME) project to assess the prediction skill of the Arctic SIE during 1982-2010 at lead times up to 9 months. Their correlation skill reached 0.78 , although it fell rapidly when the linear trends of the SIE were removed. It is worth noting that predicting the interannual variability is more difficult than predicting the total SIE anomalies. Recently, Dai et al. (2020) showed that seasonal prediction of the pan-Arctic SIE is skillful up to 12 months in advance based on the Norwegian Climate Prediction Model (NorCPM). Their results indicated that skill in predicting the regional SIE in winter is higher than that in summer.

While most of the existing assessment studies have focused on the prediction skill of the Arctic sea ice, predictability of the Arctic surface air temperature is still little known. In addition, a majority of current state-of-the-art climate models have coarse spatial resolutions and/or have poor performance in reproducing the complex multiscale ocean-atmosphere-ice interactions in the Arctic. A forecast system with improved model physics and a high-resolution is crucial to better understanding of the predictability of the Arctic climate (e.g., Haarsma et al. 2016). Here, for the first time we employ a highresolution coupled model forecast system, called the Met Office Decadal Prediction System, version 3 (DePreSys3), to assess the Arctic $\left(70^{\circ}-90^{\circ} \mathrm{N}\right)$ climate predictions at lead times from 1 to 16 months. This seasonal to interannual forecast system is used to assess to what extent the Arctic 2-m air temperature (2-m $T$ ) and sea ice cover (SIC) anomalies are predictable, and how the multidecadal trends and year-to-year variations contribute to the seasonal-to-interannual predictability there. The assessment is based on a set of ensemble hindcast experiments, built upon the Hadley Centre Global Environment Model 3-General Configuration 2 (HadGEM3GC2). A brief description of the model used in this study and reanalysis datasets employed for validation are given in section 2 . The detailed assessment results are shown in section 3 . Section 4 gives a brief summary and discussion.

\section{Model and methods}

The DePreSys3, based on the HadGEM3-GC2 (Williams et al. 2015), is a global coupled model developed at the Met
Office (Dunstone et al. 2016). This model consists of four components. The atmosphere model is Global Atmosphere, version 6.0 (GA6.0), using Even Newer Dynamics for Atmospheric Modeling of the Environment (ENDGame) to solve the nonhydrostatic, fully compressible deep-atmosphere equations of motion (Wood et al. 2014). The land surface model, called Global Land, version 6.0 (GL6.0), employs the Joint U.K. Land Environment Simulator (JULES) community model (Best et al. 2011) to simulate the land surface processes and subdaily to annual soil temperature variation (GA6.0 and GL6.0 are fully documented in Walters et al. 2017). The ocean component model Global Ocean, version 5.0 (GO5.0), which displays good performance in climate and coastal marine simulations due to updated model physics (Megann et al. 2014), is based on the Nucleus for European Modeling of the Ocean 3.4 (NEMO3.4). The Los Alamos National Laboratory sea ice model, version 4.1 (CICE v4.1; Hunke and Lipscomb 2010), is used for Global Sea Ice, version 6.0 (GSI6.0; Rae et al. 2015). It includes an energy-conserving thermodynamic model, an elastic-viscous-plastic ice dynamics model, and a transport model. For detailed description of the HadGEM3-GC2 and updated model physics relative to previous versions, readers are referred to Williams et al. (2015).

DePreSys 3 is a high-resolution initialized prediction system with a N216 horizontal resolution (about $60 \mathrm{~km}$ ) for the atmosphere and land and $0.25^{\circ}$ resolution for the ocean and sea ice. The system includes 85 atmospheric vertical levels from surface to the height of $85 \mathrm{~km}$, four soil levels, 75 levels in the ocean (Madec et al. 2013; Megann et al. 2014) and five categories of sea ice thickness (plus open water). The atmosphere/ land and the ocean/sea ice models are coupled every three hours with the OASIS3 coupler (Valcke 2013). A full-field data assimilating simulation is performed where the model is nudged in the ocean, atmosphere, and sea ice components toward observations. In the ocean, temperature and salinity are nudged toward a monthly analysis created using global covariances (Smith and Murphy 2007) with a 10-day relaxation time scale. In the atmosphere, temperature and zonal and meridional winds are nudged toward the European Centre for Medium-Range Weather Forecasts (ECMWF) reanalyses ERA-40 and ERA-Interim (Dee et al. 2011) with a six-hourly relaxation time scale. Sea ice concentration is nudged toward monthly values from the Hadley Centre Sea Ice and Sea Surface Temperature (HadISST; Rayner et al. 2003) with a 1-day relaxation time scale. Hindcasts are then started from the initial conditions of this assimilation simulation.

Thirty-member ensemble hindcasts are generated with forecast length of 16 months, and each hindcast is started on 1 November every year during 1980-2014. These ensemble members are created by using different seeds to a stochastic physics scheme in the atmosphere model (MacLachlan et al. 2015). Since the seed to generate each member keeps the same for different start years, we simply join the same-numbered member from across start dates to present the statistics of single member in an approximate way (despite there being no physical relation). In this study, we define prediction of November and December monthly mean starting from 1 November as the 1-month- and 2-months-lead forecasts, 
a) 2-m $\mathrm{T}$

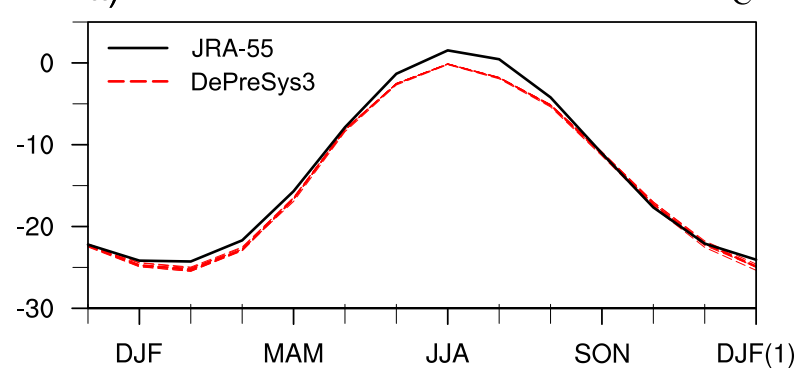

b) $\mathrm{SIC}$

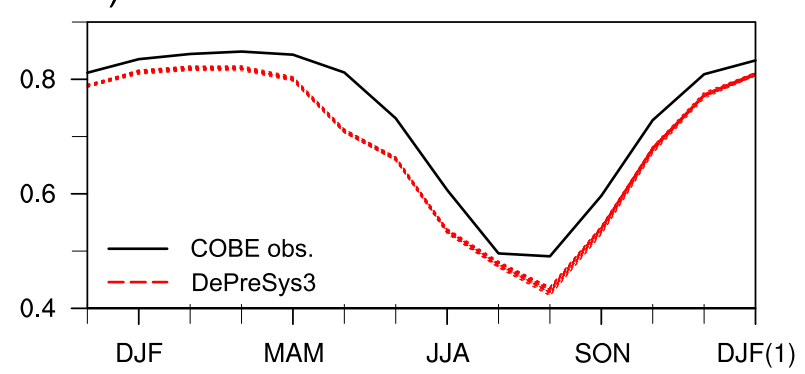

FIG. 1. The seasonal mean evolution of Arctic (a) 2-m $T\left({ }^{\circ} \mathrm{C}\right)$ and (b) SIC (fraction), based on the 1980-2014 climatology (the Arctic region is defined as north of $70^{\circ} \mathrm{N}$, including ocean and land areas for the 2-m $T$ and only ocean area for the SIC). The black solid lines indicate results that are based on the JRA-55 reanalysis and COBE observation. The red dashed lines represent each member prediction started from 1 Nov using DePreSys 3 for the target seasons of NDJ, DJF, and on until the next DJF [DJF(1)]

respectively, and so forth. To assess the seasonal to interannual skill of the hindcasts, we use the Japanese 55-year Reanalysis (JRA-55) for validation, which is given on a $1.25^{\circ}$ resolution. The variable $2-\mathrm{m} T$ is a direct output of JRA-55, and sea ice concentration is produced from Centennial ObservationBased Estimates of SSTs (COBE-SST), which is the boundary forcing used for the JRA-55 (Kobayashi et al. 2015). All model forecasts are interpolated onto the same grid as the JRA-55 reanalysis data prior to the skill assessment.

The Arctic region in this study is defined as north of $70^{\circ} \mathrm{N}$. Methods employed to assess deterministic prediction skill include simple anomaly correlation coefficient (ACC), climatological bias, and normalized root-mean-square error (RMSE) score. The ACC score measures the phase relation between the forecasts and reanalysis/observation. The prediction error is measured by the climatological bias and the RMSE normalized by one standard deviation of the reanalysis/observation. The relationship between ACC and RMSE could be described as

$$
\operatorname{RMSE}=\sqrt{\left(S_{e}^{2} / S_{o}^{2}\right)-2\left(S_{e} / S_{o}\right) \mathrm{ACC}+1}
$$

where $S_{e}$ and $S_{o}$ are the corresponding standard deviations of the ensemble prediction and reanalysis/observation, respectively (Merryfield et al. 2013). High ACC values and low RMSE values are both indicative of good prediction performance. Linear regression and composite analyses are also

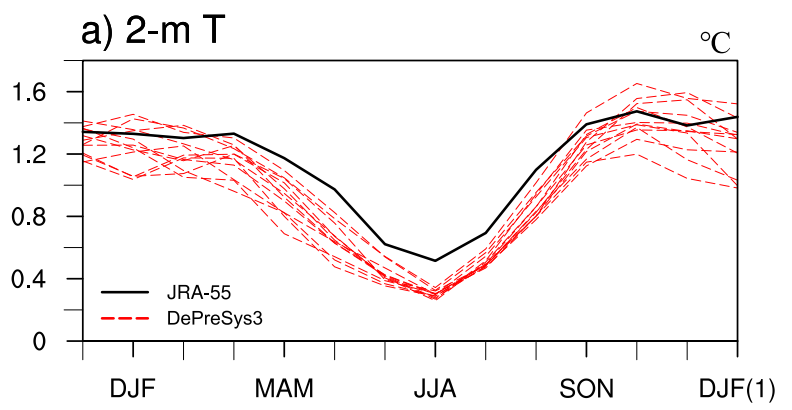

b) SIC

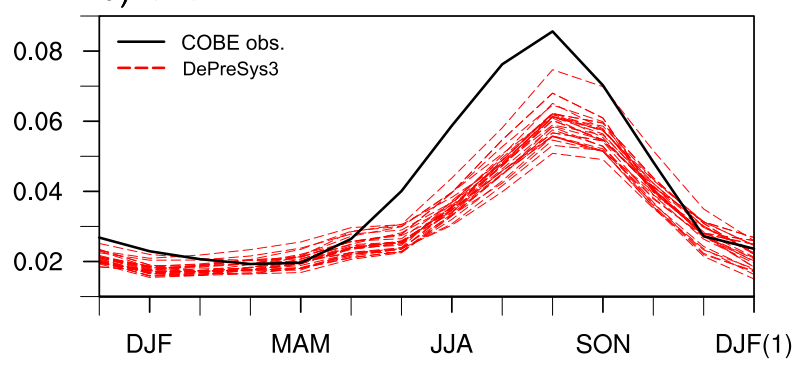

FIG. 2. As in Fig. 1, but for the standard deviation of the Arctic (a) 2-m $T\left({ }^{\circ} \mathrm{C}\right)$ and (b) SIC (fraction).

employed in this study. All of the results are examined for statistical significance at the $95 \%$ confidence level using Student's $t$ test.

\section{Results}

\section{a. Assessment of climatology and variability}

To examine how well the model predicts the mean state and variability of Arctic climate, we first compare the reanalysis/ observation and predicted climatological (1980-2014) 2-m T and SIC over the Arctic (Fig. 1). Encouragingly, DePreSys3 shows good performance in reproducing the mean state of 2-m $T$ and SIC over the Arctic. Although the surface air temperature in boreal summer is slightly underestimated (Fig. 1a), the climatology is well predicted by all members. Similar to other regions in the Northern Hemisphere, the Arctic 2-m $T$ is highest in summer [June-August (JJA)] and lowest in winter [December-February (DJF)]. For the Arctic-averaged SIC, the members underestimate sea ice cover in all target seasons compared to the observations. However, the predictions can well capture the seasonal evolution features, namely the Arctic sea ice begins to melt in spring [March-May (MAM)] and reaches the minimum around autumn [August-October (ASO)]. This is also consistent with satellite observations displayed in Johannessen et al. (2004).

The standard deviations of interannual variability of the 2-m $T$ and SIC over the Arctic are displayed in Fig. 2. The results indicate that most of the members underestimate the interannual variance of Arctic 2-m $T$, especially during boreal summer (lead times of 8-10 months; Fig. 2a). In general, each ensemble member can realistically reproduce the seasonal evolution of 

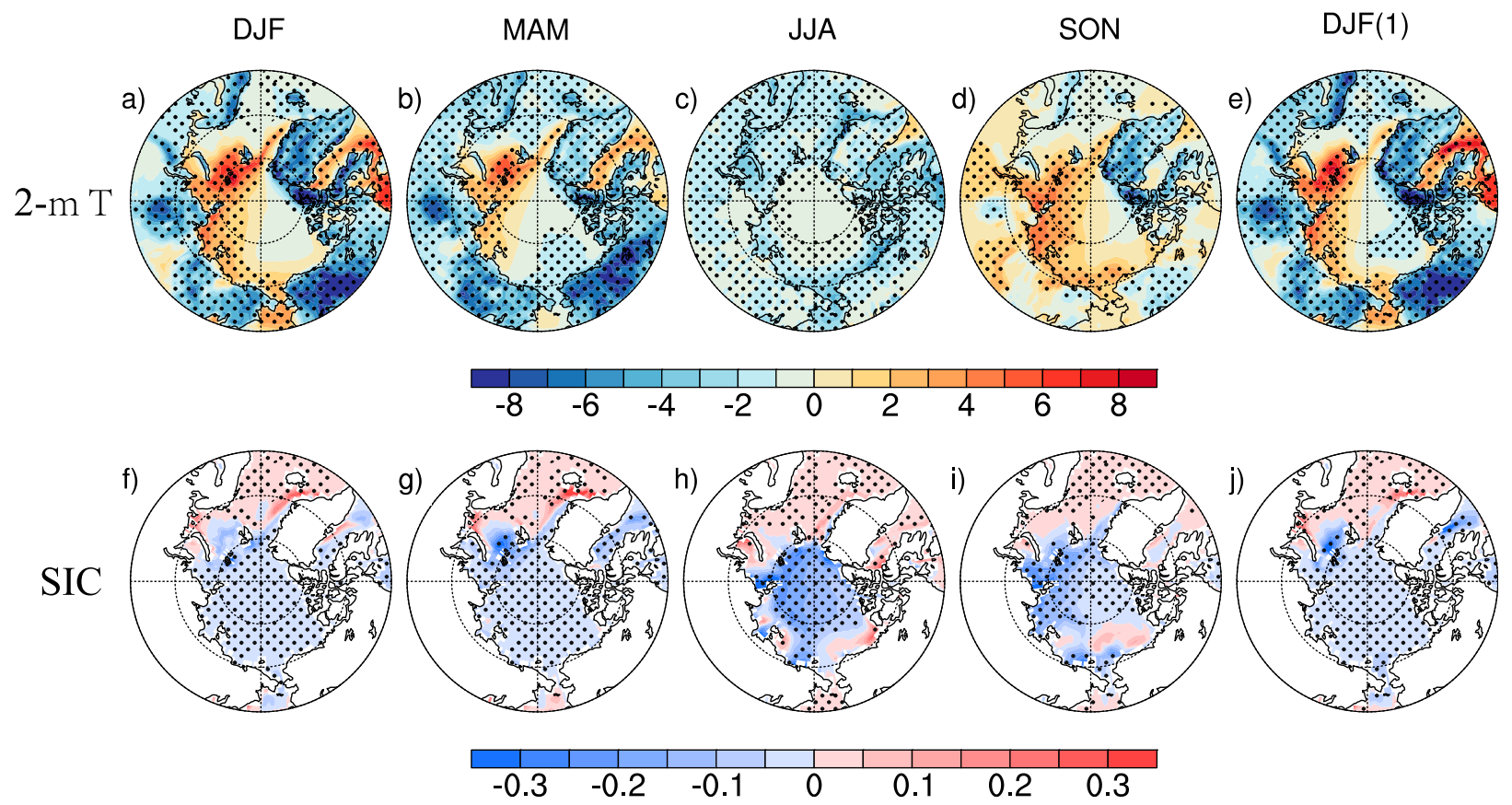

FIG. 3. The climatological (1980-2014) biases (i.e., climate drifts) for (top) 2-m T and (bottom) SIC during (a),(f) December-February (2-4-months lead); (b),(g) March-May (5-7-months lead); (c),(h) June-August (8-10-months lead); (d),(i) September-November (11-13-months lead); and (e),(j) the next December-February (14-16-months lead). Stippling indicates that the biases are statistically significant at the $95 \%$ confidence level. The dashed midlatitude circle in each panel denotes $70^{\circ} \mathrm{N}$, the regions north of which is the Arctic as defined in this study.

the interannual variability of the Arctic 2-m $T$. Similar to the results of Johannessen et al. (2016), its variance in JJA is the smallest, and reaches the maximum in boreal winter. In contrast, the interannual variability of the Arctic SIC increases from early boreal spring, peaks in ASO, and starts to decline in autumn (Fig. 2b). Most areas of Arctic are covered by sea ice during the freezing period of the year, so the interannual variability of SIC is small in winter and large in the melting season, which is consistent with Holland et al. (2010). DePreSys3 shows a good performance in reproducing the seasonal evolution of the variance of Arctic sea ice at lead times of up to 16 months.

Spatial distributions of the model biases in the predicted climatological 2-m $T$ and SIC for 5 target seasons (i.e., at lead time of $2-4,5-7,8-10,11-13$, and $14-16$ months) are displayed in Fig. 3. Significant warm biases appear over the east of the Arctic region except JJA and weak cold biases appear over the west of the Arctic region in all target seasons. Specifically, DePreSys3 overestimates the air temperature over the Barents-Kara Seas, the Laptev Sea, and eastern Siberian Sea, especially in boreal winter, but underestimates the 2-m $T$ in the Greenland at all lead months. At 8-10-months lead (i.e., JJA), the predicted 2-m $T$ is colder than the reanalysis across the entire Arctic region. However, magnitudes of the temperature biases in many regions of the Arctic in this season are the smallest among the five target seasons (but still statistically significant). Thus, the good representation of the climatological seasonal cycle of the Arctic mean 2-m $T$ at most lead times (recall Fig. 1a) is likely because the regional errors are compensated for each other when calculating the Arctic mean values. As for the Arctic SIC prediction, it is shown that significant underestimation appears in most region of the Arctic Ocean in all target seasons. Larger predicted SIC biases exist in the Barents Sea, the Baffin Bay, and the Beaufort Sea at lead times of 8-13 months. Less bias occurs over these regions in other target seasons.

In summary, DePreSys3 is able to well capture the climatological 2-m $T$ and SIC as well as their interannual variabilities over the Arctic, albeit with biases and discrepancies in some target seasons and regions. The high-resolution DePreSys3 also shows a good performance in representing local features in the Arctic. The climatology and variability of the averaged 2-m $T$ and SIC over the Arctic are both well reproduced at lead times of up to 16 months; this provides a promising basis for the following skill assessment and analysis.

\section{b. Seasonal-to-interannual prediction skill assessment}

In this section, prediction skill of seasonal mean anomalies in the Arctic at lead times of up to 16 months are assessed based on the DePreSys3 30-member ensemble hindcasts during 1980-2014. We note that the model's climate drifts have been removed by calculating the predicted anomalies relative to the climatology of the model forecasts at each lead time when assessing the model predictive skills.

\section{1) Prediction of SEASONAL ANOMALies}

Correctly predicting the regional anomalies is challenging since the Arctic climate is controlled by complex processes/ 

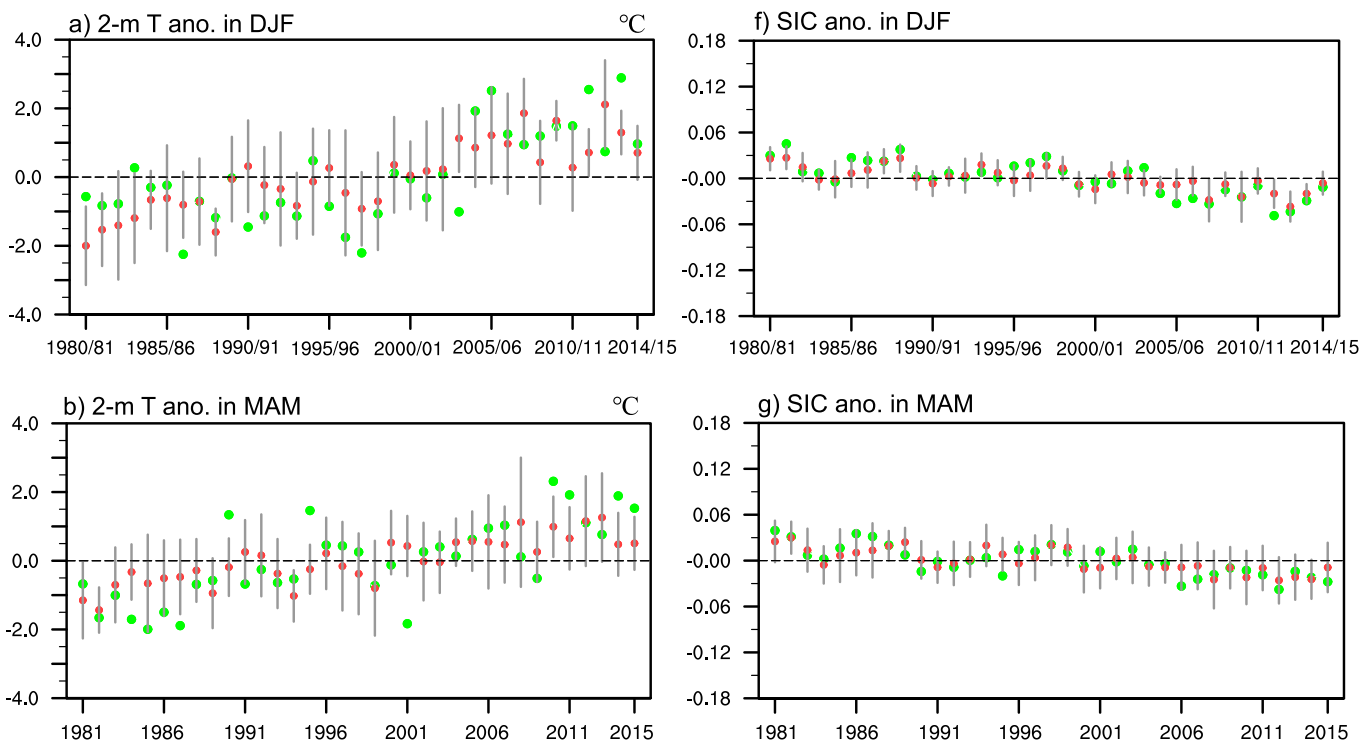

g) SIC ano. in MAM
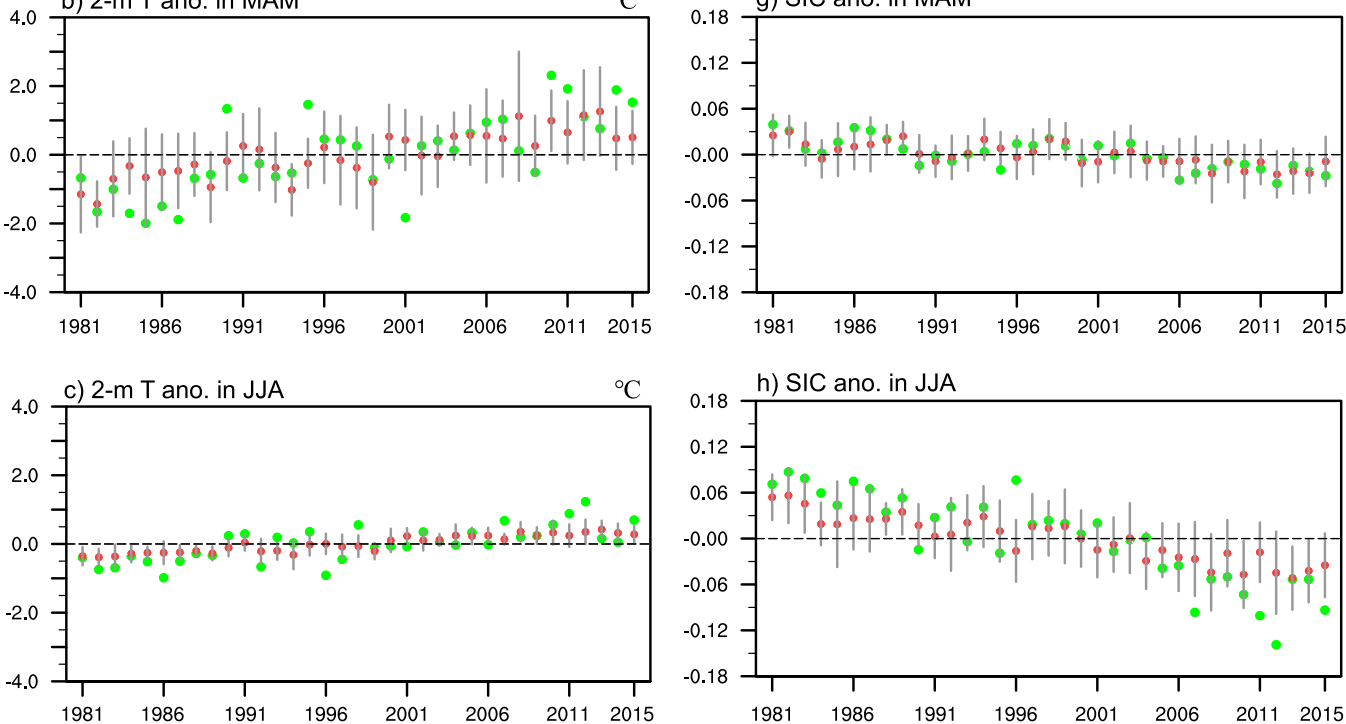

h) SIC ano. in JJA
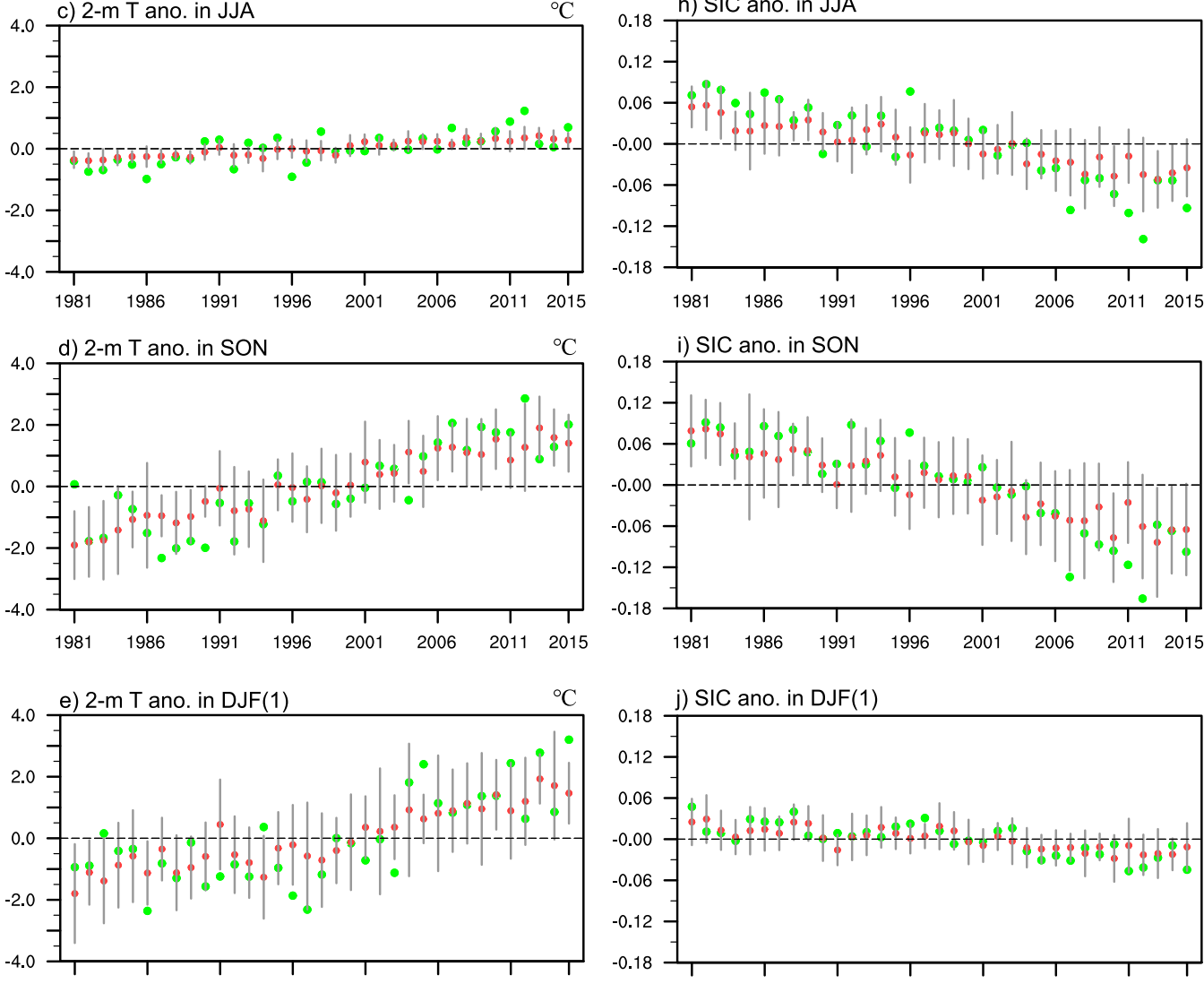

$\begin{array}{lllllll}1981 / 82 & 1986 / 87 & 1991 / 92 & 1996 / 97 \quad 2001 / 02 & 2006 / 07 & 2011 / 12 & 2015 / 16\end{array}$

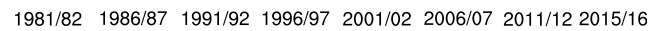

FIG. 4. Predictions of the Arctic-averaged (a)-(e) 2-m $T$ and (f)-(k) SIC anomalies for each target season during 1980-2014. The green and red dots represent the reanalysis/observation and ensemble mean predictions, respectively. The gray vertical lines denote the minimum-to-maximum range of the 30 member predictions.

mechanisms. Encouragingly, the Arctic mean 2-m $T$ and SIC anomalies in each target season during most years of 1980 2014 are reasonably well predicted by the DePreSys3 ensemble forecasts in Fig. 4. Although, as expected, the ensemble mean predictions underestimate the reanalysis/observation magnitudes, most of the reanalysis/observation values are well covered within the spread of the 30 members. This is true for the predictions of both 2-m $T$ and SIC anomalies even at long lead times. And the 
a) 2-m T ACC

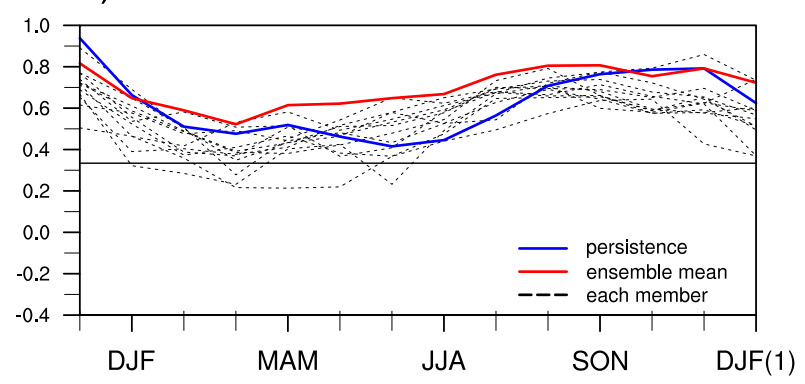

b) SIC ACC

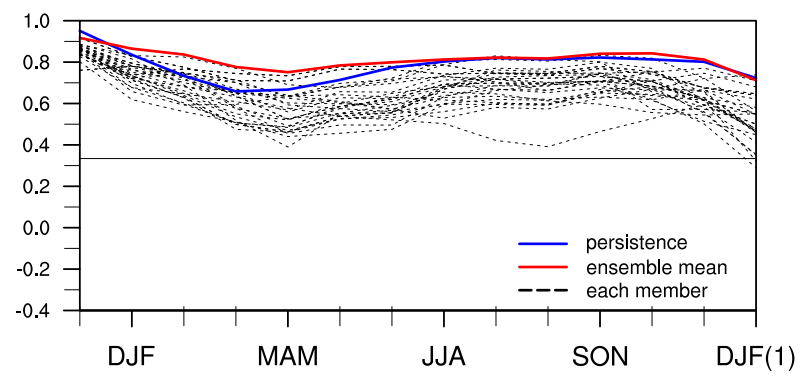

FIG. 5. Anomaly correlation coefficient skills in predicting the seasonal mean Arctic-averaged (a) 2-m $T$ and (b) SIC for each target season on the basis of the DePreSys3 30-member ensemble hindcasts initiated from 1 Nov of every year during 1980-2014. The black dotted lines represent ACC skills of each member, and the blue and red solid lines indicate persistence and ensemble mean ACC skills, respectively.

strong multidecadal increase (decrease) trend of the Arctic 2-m $T$ (SIC) during 1980-2014 is well simulated. In addition, the seasonal variations of the Arctic SIC appear to be better predicted out to 16-months lead except a few false alarms, relative to the predictions of the Arctic 2-m T. Some of the extreme low Arctic SICs during JJA and September-November (SON) after 2005 are also realistically predicted by the DePreSys 3 ensemble members.

Figure 5a shows the anomaly correlation coefficients (ACC) of 3-month running mean 2-m $T$ of the Arctic between the predictions and reanalysis anomalies as a function of the lead time. The results suggest that the Arctic-averaged 2-m $T$ can be well predicted (i.e., correlation skill is statistically significant) at lead times of up to 16 months, despite that the skill is slightly lower than the persistence within the first season. The skills reach greater than 0.7 in July-September (JAS), ASO, SON, and out to the next boreal winter [December-February(1): $\mathrm{DJF}(1)]$. As expected, skill of the ensemble mean prediction is almost always higher than that of individual members.

Figure 6 displays the spatial distributions of the DePreSys 3 30-member ensemble mean prediction skills of 2-m $T$ in each grid of the Arctic for five target seasons. The normalized RMSEs of the ensemble mean predictions are also displayed for each of the target seasons. Usually, the higher the ACC skill is, the smaller the normalized RMSE is. The results suggest that, while the ACC skills are hard to beat the persistence forecast skills for the first season (i.e., DJF), DePreSys3 outperforms the persistence for the other target seasons in most areas of the Arctic when the lead time increases (upper panel, Fig. 6). Statistically significant skills are found in larger part of the Arctic for the target seasons except JJA. It is worth noting that the significant skills reemerge in boreal autumn, as is also shown by the rebound of the persistence in SON (recall Fig. 5a). Interestingly, skillful predictions with high ACC values and low normalized RMSE scores appear over almost the entire Arctic Ocean at lead times of 11-13 months (i.e., SON); this indicates an interannual predictability of the 2-m air temperature in the Arctic. In general, predictive skill of the seasonal mean 2-m $T$ is relatively low in the Laptev Sea as compared with other regions over the Arctic. Among the five target seasons, the 2-m $T$ anomalies are the least predictable in the following summer (JJA). Over the Barents Sea, the seasonal mean 2-m $T$ anomalies are predictable at the lead times out to 8 months, with the areas of the significant prediction shrinking in the following autumn and winter.

The ACC skill of SIC prediction is shown in Figs. 5b and 7. The seasonal mean Arctic-averaged SIC is highly predictable out to 16 months ahead (ACC $\geq 0.7$ ), in association with its high persistence. Not surprisingly, skill of the ensemble mean prediction is greater than that of individual members. In addition, the ensemble mean prediction of the SIC anomalies is more skillful than that of 2-m $T$ over the Arctic region, particularly at the lead times of the first 10 months (cf. Figs. 5a,b). Compared to the results of Chevallier et al. (2013), which displayed ACC score of 0.74 in predicting the Arctic SIE at lead times out to 4 months using the CNRM-CM5.1 model with a $1.4^{\circ}$ horizontal resolution, the high-resolution DePreSys3 produces ACC score of greater than 0.8 out to 6 months of lead time (Fig. 5b). Moreover, the DePreSys3's ACC prediction skill of the Arctic sea ice in JJA target season is also higher than that of the CFSv2 model with a coarse resolution (Wang et al. 2013).

Comparing with the persistence forecast, DePreSys3 produces better skill over many parts of the Arctic, except for the first and the next boreal winter (Fig. 7). Significant skills in predicting the sea ice in Barents Sea occur across all the target seasons, and the predictable areas are extended in the first winter as well as the following summer and autumn. However, statistically significant skill in predicting the SIC over the eastern Siberian Sea and the Chukchi Sea is only visible at the 8-10- and 11-13-months lead. For the Arctic Ocean, significant skill appears over almost the entire region at lead times of 11-13 months (i.e., SON, Fig. $7 \mathrm{~g}$ ). The rebound of skill in SON is also visible in Fig. 7, similar to that of the Arctic 2-m T prediction (recall Figs. 5a and 6). This is consistent with the reemergence mechanisms suggested by Blanchard-Wrigglesworth et al. (2011), Chevallier et al. (2013), and Day et al. (2014).

\section{2) IMPACT OF THE TREND}

Previous studies demonstrated that the strong multidecadal trends contribute to a large amount of the prediction skill of the Arctic climate (e.g., Sigmond et al. 2013; Harnos et al. 2019). For instance, Lindsay et al. (2008) found that the trend in September sea ice extent in the Arctic accounts for $76 \%$ of its total variance and therefore provides most of its seasonal 

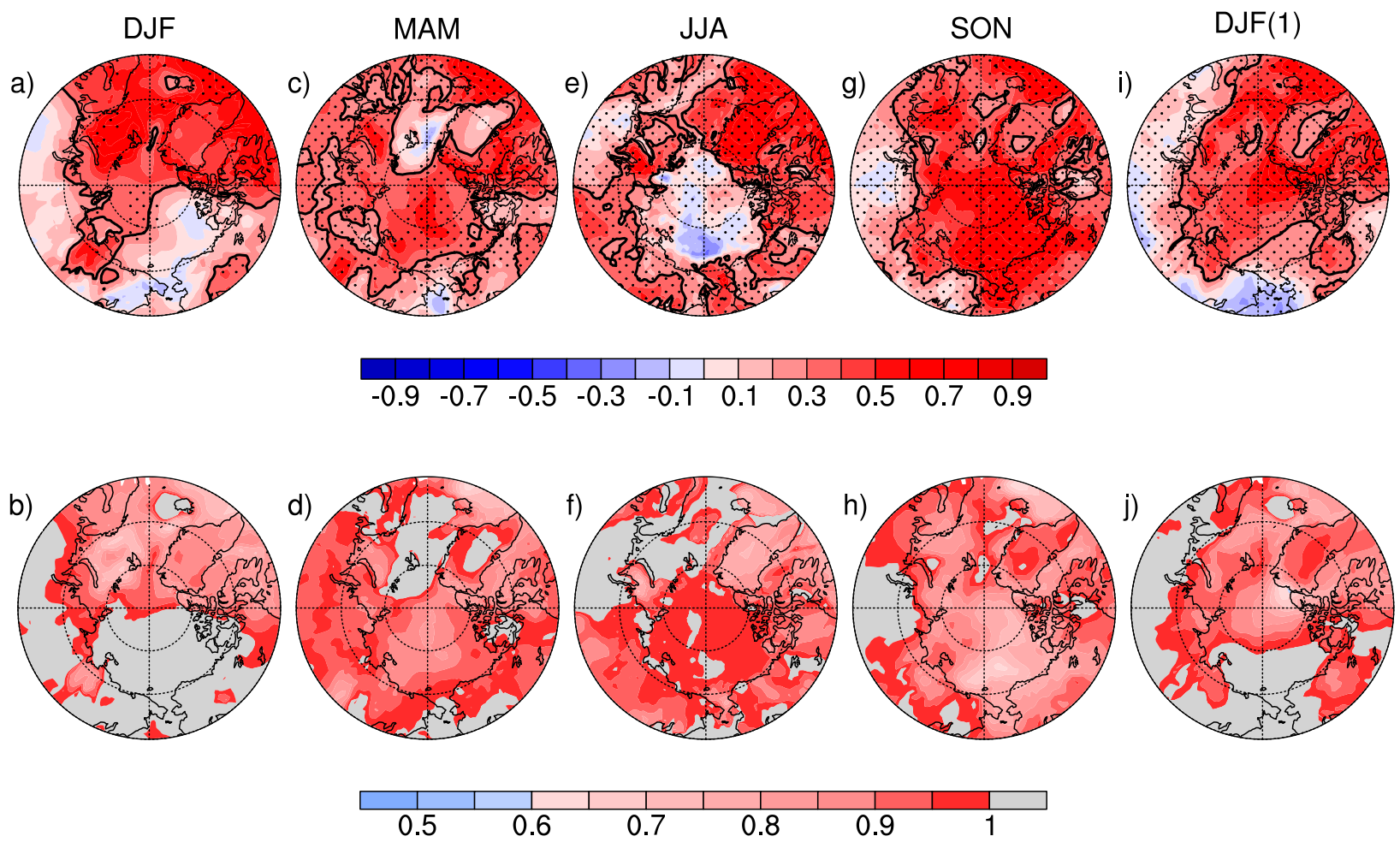

FIG. 6. (top) Anomaly correlation skill and (bottom) RMSE of 2-m $T$ over the Arctic during (a),(b) December-February (2-4-months lead); (c),(d) March-May (5-7-months lead); (e),(f) June-August (8-10-months lead); (g),(h) September-November (11-13-months lead); and (i),(j) December-February (14-16-months lead). The skills are calculated on the basis of ensemble mean predictions and the JRA-55 reanalysis. Stippling in the top panels indicates that the skills are better than a persistence forecast, and black solid lines represent statistical significance at the $95 \%$ confidence level, estimated with the effective number of degrees of freedom. The RMSEs have been normalized by 1 standard deviation of the observations.

predictability. Consistently, DePreSys3 shows good skill in capturing the strong observed trends of the temperature increase and sea ice cover decrease in the Arctic during 19802014 (Fig. 4). To examine the contributions of the multidecadal trends to the high seasonal-to-interannual prediction skills in DePreSys3, linear trends of the Arctic 2-m T and SIC anomaly during 1980-2014 for each target season are displayed in Figs. $8 \mathrm{a}$ and $8 \mathrm{~b}$. The multidecadal increasing of the $2-\mathrm{m} T$ and the reduction of the sea ice occur over the Arctic across all seasons. The ice-albedo positive feedback may be partly responsible for these amplified trends in the Arctic (e.g., Chylek et al. 2011). As the greenhouse gases' concentrations increase, the warming Arctic causes sea ice to melt a lot. The more open water leads to the decrease of surface albedo, and the more solar radiation is absorbed. Consequently, sea ice melts more quickly and surface temperature becomes warmer than before in the Arctic. The results indicate that DePreSys 3 captures the amplified trends well, despite that the ensemble mean predictions underestimate the amplitudes of the trends of the Arctic 2-m $T$ and SIC in all target seasons.

The warming trend of Arctic 2-m $T$ weakens from boreal winter to following summer, reaching a minimum in JJA, and then intensifies to a maximum in late autumn [October-December (OND); Fig. 8a]. In association with the seasonal migration of solar radiation, the Arctic sea ice begins to melt in early spring and continues to melt in summer, absorbing heat from the lower atmosphere. In recent years, the sea ice melting over the Arctic has intensified (Fig. 8b; Serreze and Stroeve 2015), so the air temperature warming trend during the melt seasons is not so obvious as that in other seasons. In contrast, in September when the freezing period starts, the sea ice releases a large amount of latent heat to the atmosphere; this further warms up the Arctic temperature (e.g., Bintanja and van der Linden 2013). While the warming trends peak in boreal autumn and winter, the trends of the sea ice cover reduction become the lowest since the entire Arctic is almost fully covered by thick ice in the two seasons (Fig. 8b). Once the melting season starts, the trend of the sea ice cover reduction increases quickly and reaches a maximum in early autumn (ASO) when the seasonal climatology of the SIC is the minimum (recall Fig. 1b). This indicates that more and more open water has been exposed in the melting seasons in recent decades, leading to a wider ice-free Arctic in the summer and autumn. These seasonal distributions of the apparent 2-m $T$ and SIC trends in the Arctic are well predicted by DePreSys3.

One distinctive feature is that the SON peak value of the seasonally varying warming trend lags the ASO maximum of the seasonally varying sea ice decrease trend for about 1 month, which was pointed out by Screen and Simmonds 

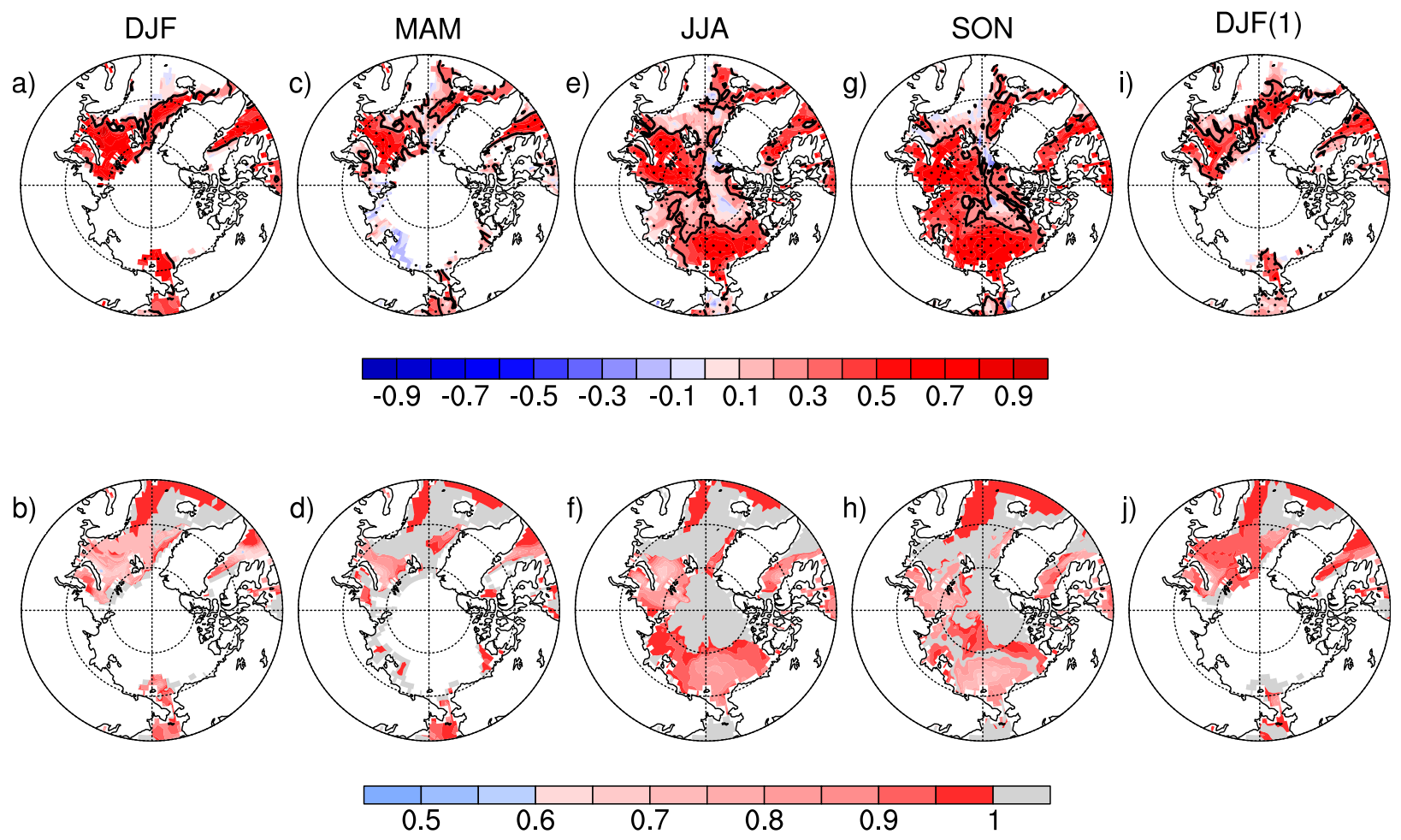

FIG. 7. As in Fig. 6, but for the SIC predictions. Skills are not shown for the areas with permanent sea ice cover during each target season.

(2010). To further understand this phase relation, we first examine the trends of the seasonal tendency of the Arcticaveraged SIC (i.e., the trend of the difference between the SIC in next season and that in this season). The trends of the seasonal tendencies of the Arctic SIC are negative during the melting seasons but positive during the freezing seasons (Fig. 8c). This suggests that the Arctic sea ice has melted faster in spring and summer but also grown faster in autumn than before. This is consistent with the study of Comiso and Hall (2014), who pointed out that the total amount of the Arctic sea ice has decreased drastically since the end of the twentieth century, but the growth of the seasonal ice is also increasing in the freezing seasons. In other words, the ice melting and water freezing over the Arctic occur more intensively, and the heat exchange between the ocean and the atmosphere increases. DePreSys3 successfully predicts the changes of the Arctic seasonal SIC tendencies, albeit the magnitudes are underestimated. Note that, the predicted SIC tendency change is nearly zero during April-June, in contrast to the rapid SIC decrease in the observation. In the DePreSys3, the rapid decrease of the SIC delays for about one month (Fig. 8b).

The seasonally varying trends of the Arctic-averaged 2-m $T$ anomaly and the SIC tendency display a good in-phase relation (cf. Figs. 8a,c). To further explore this relationship, we calculate the trends of seasonal mean surface heat fluxes (downward positive) over the Arctic during 1980-2014, based on the JRA55 reanalysis (Fig. 9). The surface net heat flux (i.e., the purple solid line in Fig. 9) shows that, during the melting season, increased energy is input into the ocean to heat the water and melt sea ice, especially in late spring and summer over recent decades. This is mainly due to the increase of net shortwave radiation flux with a modest contribution from the long wave radiation increase (orange and green dashed lines in Fig. 9). The decreasing sea ice cover leads to more open water to absorb more solar radiation and store more energy in the Arctic Ocean. The increasing areas of open water in the Arctic may in turn affect the warming rate due to the large heat storage capacity of the ocean surface layer. From September when the freezing starts, the Arctic Ocean releases the previously stored energy to heat the atmosphere. The increased latent heat flux warms up the surface air more, as is indicated by the largest trend of turbulent flux in SON (blue dashed line in Fig. 9). The strong upward turbulent flux in boreal autumn and winter leads to the large warming trends of the Arctic 2-m $T$ in these seasons (recall Fig. 8a).

\section{3) Prediction of nAtural VARiations (i.E., DETRENDED ANOMALIES)}

The high prediction skills of the Arctic 2-m $T$ and SIC anomaly in each target season appear to be largely attributed to the strong multidecadal trends as was discussed above. Lindsay et al. (2008) found that, after detrending the Arctic SIE in September, no significant skill was found at lead time beyond 3 months. If simply using the multidecadal linear trends of the Arctic climate to represent the response driven by external radiative forcing like greenhouse gases' emissions (Screen et al. 2013; Serreze and Barry 2011), predictive skills of the 2-m $T$ and SIC anomaly after the linear trends are 
a) Arctic 2-m Tanomalies

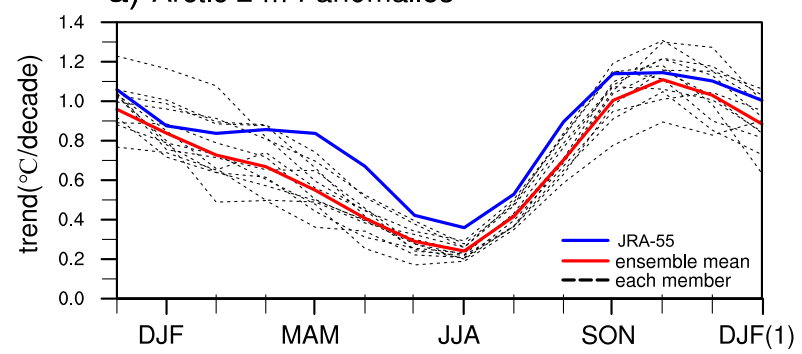

b) Arctic SIC anomalies

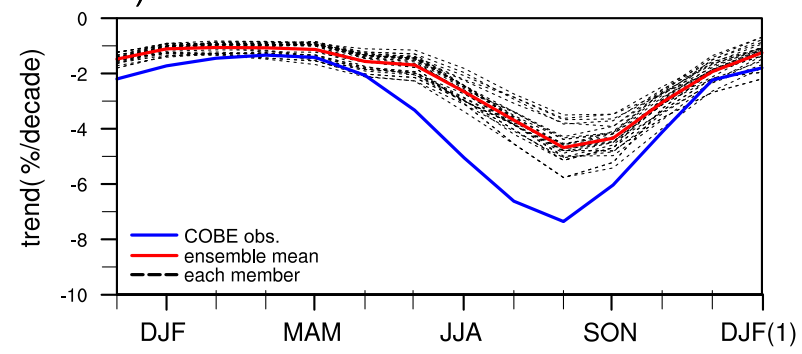

C) tendency of Arctic SIC anomalies

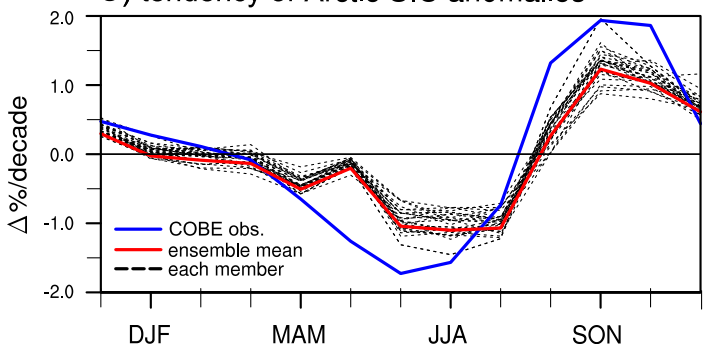

FIG. 8. Trends of the Arctic-averaged (a) 2-m $T$ anomalies $\left({ }^{\circ} \mathrm{Cdecade}^{-1}\right),\left(\right.$ b) SIC anomalies $\left(\%\right.$ decade $\left.^{-1}\right)$, and (c) seasonal tendency of SIC anomalies $\left(\Delta \%\right.$ decade $^{-1}$; e.g., the tendency of the SIC in JJA is calculated by the difference between the SIC in JAS and that in JJA) during 1980-2014 for each target season. The ensemble mean predictions are shown in red, and the JRA-55 reanalysis and COBE observation are displayed in blue. Black dotted lines indicate individual members.

removed would tell how well the DePreSys 3 predicts internally generated variations. Predictions of the detrended anomalies in the target seasons are displayed in Fig. 10. While a certain amount of the observational detrended anomalies is captured by the ensemble members, there are many discrepancies between the model ensemble mean predictions and the reanalysis/observations during 1980-2014. The model performs well only at short-lead months in a few years; large prediction errors and false alarms are visible in the hindcasts of both the Arctic 2-m $T$ and SIC detrended anomalies.

We further examine the forecast skill of the natural variations after the linear trends are removed (Fig. 11). The results suggest that the detrended Arctic mean 2-m $T$ anomaly has very limited prediction skills at all the lead times, except the statistically significant ACC in the first season [November-January (NDJ), Fig. 11a]. During the early

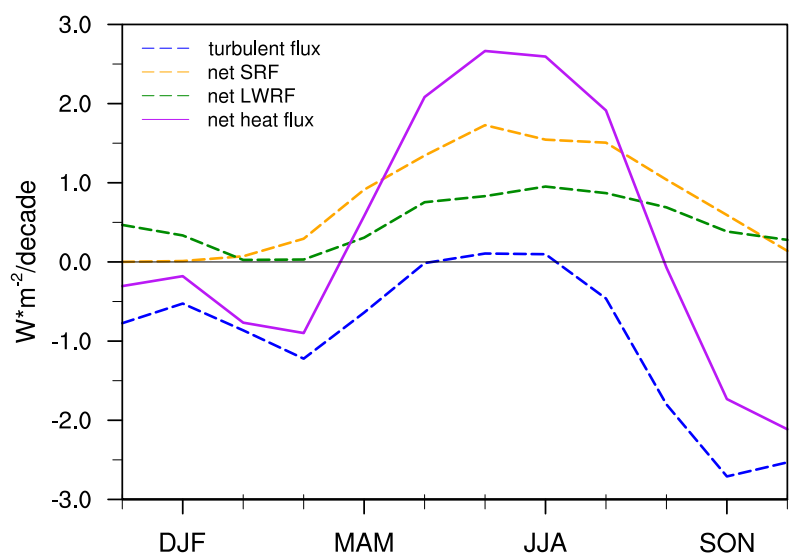

FIG. 9. Trends of the Arctic-averaged seasonal mean surface heat flux anomalies [ $\mathrm{W} \mathrm{m}^{-2}$ decade $^{-1}$ (downward positive)], obtained from the JRA-55 reanalysis. The purple solid line indicates the trend of surface net heat flux. Blue, orange, and green dashed lines represent turbulent (sensible + latent) flux, net shortwave radiation flux, and net longwave radiation flux, respectively.

spring [February-April (FMA)] to the following late autumn (OND), the ACC skills are as low as the climatology forecast (i.e., ACC $=0$ ). Figure 12 shows statistically significant prediction skill over the Barents Sea in DJF, but low skills and even negative ACC skills appear over major regions of the Arctic at middle and long lead times. The ACC prediction skill of the detrended Arctic SIC anomaly is better than that of the 2-m $T$, with the statistically significant prediction skill appearing up to about 7 months of lead time (Fig. 11b), which is also higher than the skill of Sigmond et al.'s (2013) dynamical forecast system. The ACC values are also better than the climatology forecast except those at lead times of 8-13 months. When compared with the NMME predictions with totally 58 members for the detrended Arctic mean SIE during 1982-2010 (Harnos et al. 2019), the DePreSys3 also shows relatively higher ACC skill in the first boreal winter. Encouragingly, the prediction skill of the detrended SIC anomaly is higher than the persistence forecast out to May-July (MJJ) and the difference is statistically significant in the first winter and spring. This indicates a relatively high seasonal predictability of the detrended SIC. Holland et al. (2010) also found a similar result and suggested that the high short-lead predictability of the detrended SIC in boreal winter is related to the interaction between the sea ice edge and convergence of ocean heat fluxes (Bitz et al. 2005). In addition, relatively good prediction skills of the detrended Arctic SIC anomalies are found in Barents Sea at lead times of up to 11-13 months (Fig. 13). For the target seasons of JJA and SON, statistically significant and higher-than-persistence ACC skills appear over parts of the Arctic Ocean.

In summary, the high seasonal-to-interannual prediction skills of the Arctic climate are predominantly attributed to the strong multidecadal trends over the past decades under global warming. In contrast, the internal variability of the Arctic temperature and sea ice is less predictable at seasonal-tointerannual lead times. Nevertheless, the Arctic detrended 

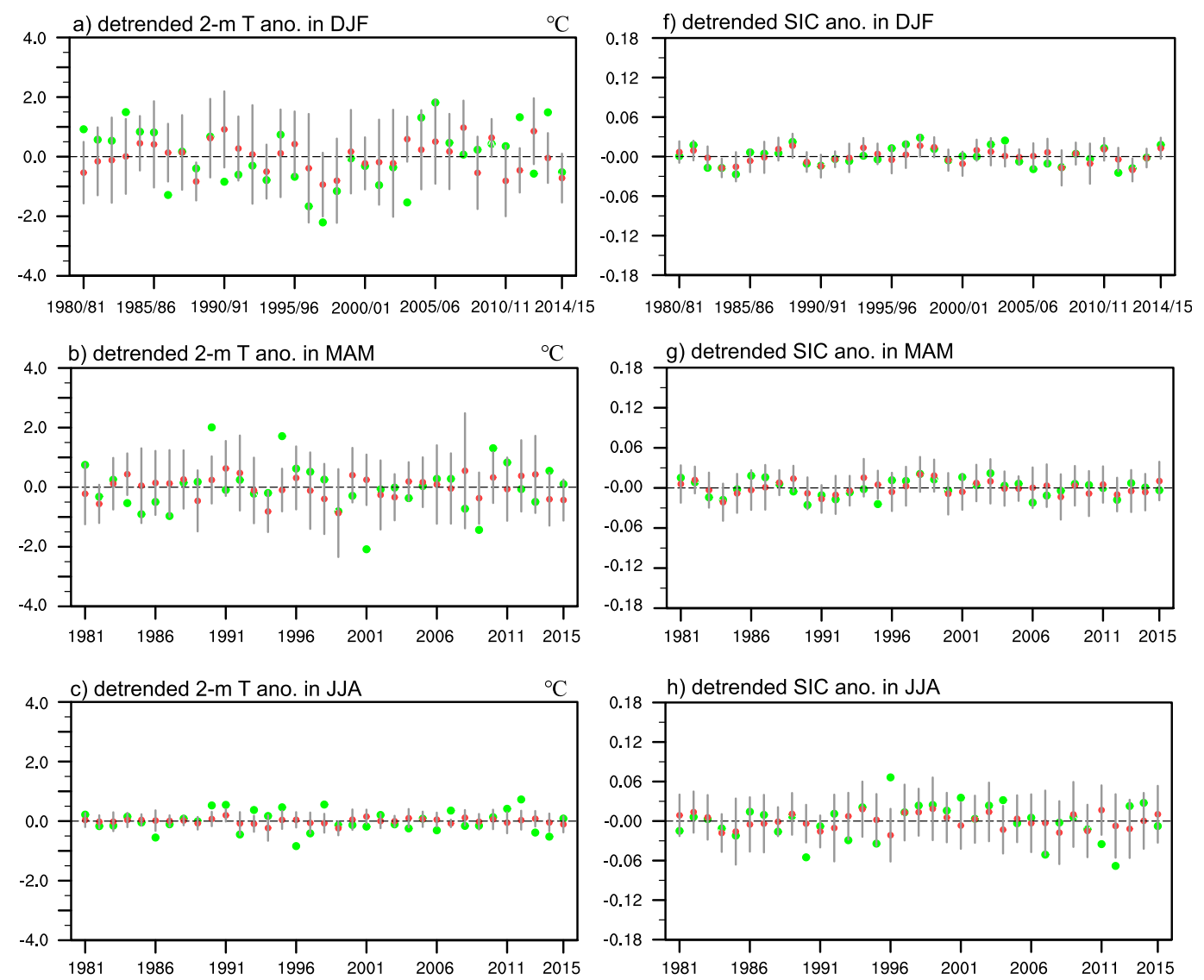

h) detrended SIC ano. in JJA
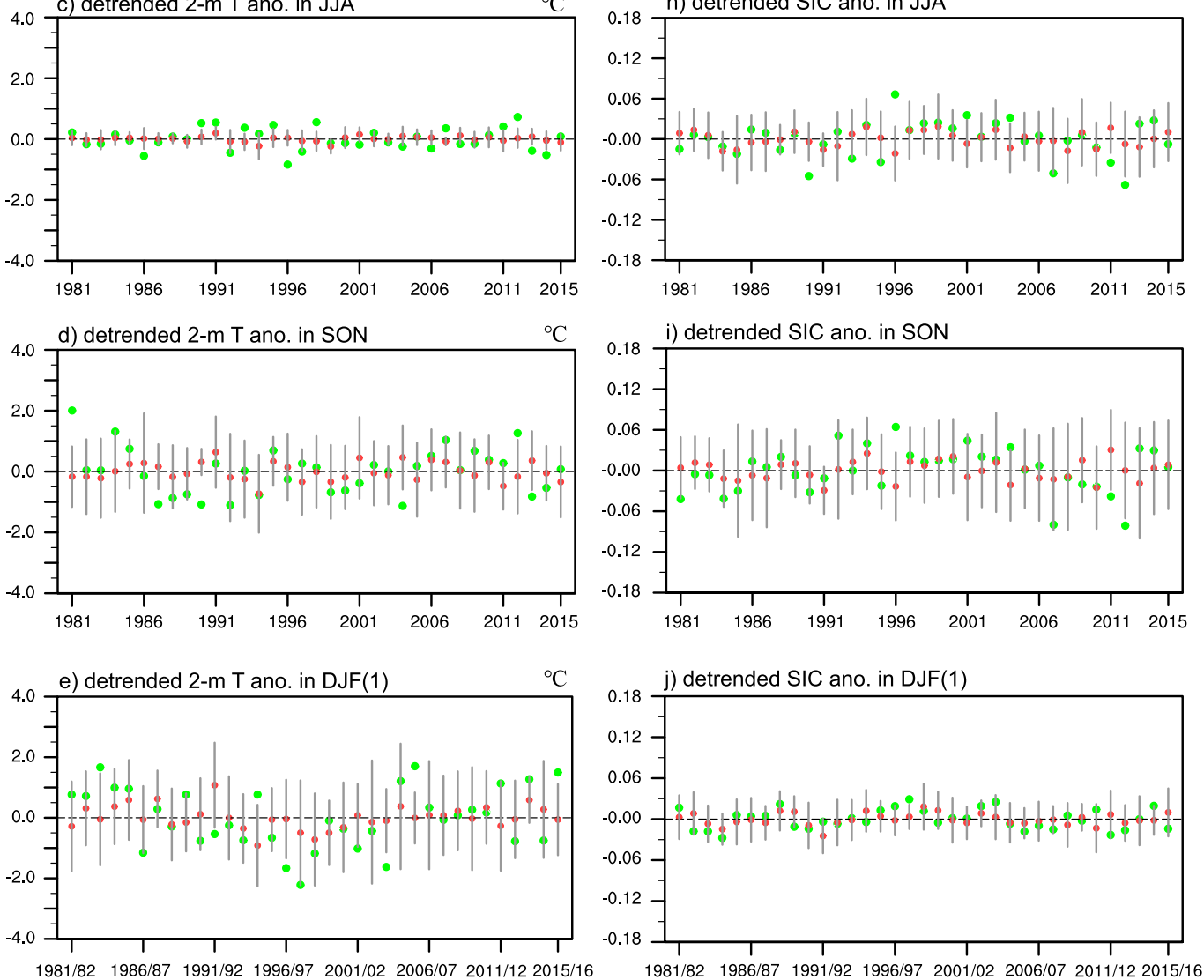

FIG. 10. As in Fig. 4, but for the predictions of the detrended anomalies.

anomalies in boreal winter (DJF) in many years can be predicted reasonably well at the short lead time (Figs. 10 and 11). Note that, while the prediction skill (ACC) of the detrended Arctic mean SIC anomalies in the first winter season reaches about 0.7 , the variance of the sea ice cover in the freezing winter season is small (similar to Fig. 2b; figures not shown). Thus, we will pay more attention to the possible factors that contribute to the predictability of the internal variability of the Arctic $2-\mathrm{m} T$ in boreal winter, during which the variance of the $2-\mathrm{m} T$ is large (similar to Fig. 2a; figures not shown). 


\section{a) 2-m T ACC}

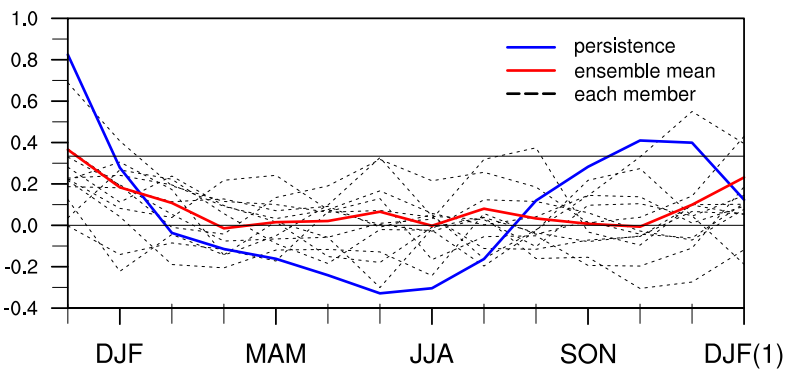

\section{b) SIC ACC}

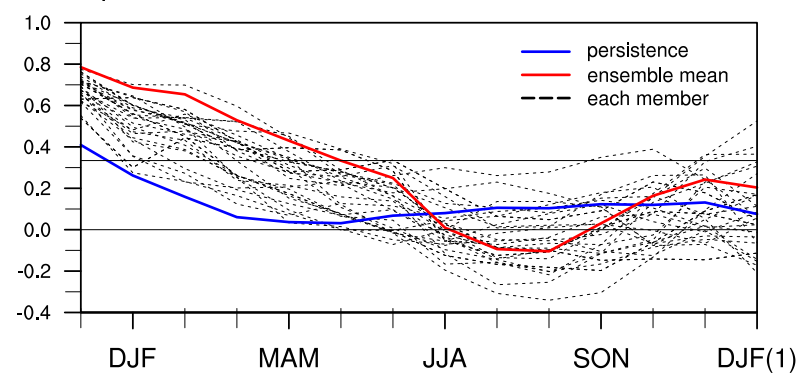

FIG. 11. As in Fig. 5, but for the detrended anomalies.

\section{c. ENSO impact on the Arctic internal variations in winter}

Previous studies suggested that internal modes of climate variability, such as the North Atlantic Oscillation (NAO)Arctic Oscillation (AO) (Mysak and Venegas 1998; Kwok
2000; Rigor et al. 2002; Krahmann and Visbeck 2003; Zhang et al. 2004) and the Madden-Julian oscillation (Yoo et al. 2011), play important roles in the Arctic climate variations. Tropical sea surface temperature (SST) also has important contributions to the recent Arctic warming (Lee et al. 2011; Ding et al. 2014). In particular, El Niño-Southern Oscillation (ENSO), as a dominant internal climate variability mode can largely impact Arctic climate by forcing poleward-propagating atmospheric Rossby waves (Sassi et al. 2004; Lee 2012; Hu et al. 2016). Here, we explore whether the highly predictable ENSO could contribute to predictability of the internal variations of the Arctic climate. The short-lead predictions of the detrended Arctic anomalies in winter (DJF) are much closer to the observation in El Niño and La Niña years, relative to the large discrepancies in ENSO neutral years (recall Fig. 10a). Thus, understanding the impacts of ENSO on the Arctic climate prediction is of profound interest.

In Fig. 14a we show the relationship between the predictions of the detrended Arctic 2-m $T$ anomalies and ENSO, using the Niño-3.4 index from the National Oceanic and Atmospheric Administration (NOAA) Extended Reconstructed Sea Surface Temperature, version 5 (ERSST V5). The results suggest that, in most of ENSO years (denoted by red and blue filled circles), the spatial distributions of the detrended 2-m $T$ anomalies in the Arctic can be predicted reasonably well (pattern correlation skill $>0$ ). During El Niño or La Niña events, pattern correlations are relatively high. As was shown in Fig. 10a, the predicted anomalies are close to the reanalysis when ENSO events occur, such as in 1989, 1998, 2002, and 2009. In contrast, the numbers of positive and negative pattern correlation skills (black solid and hollow circles) are nearly the
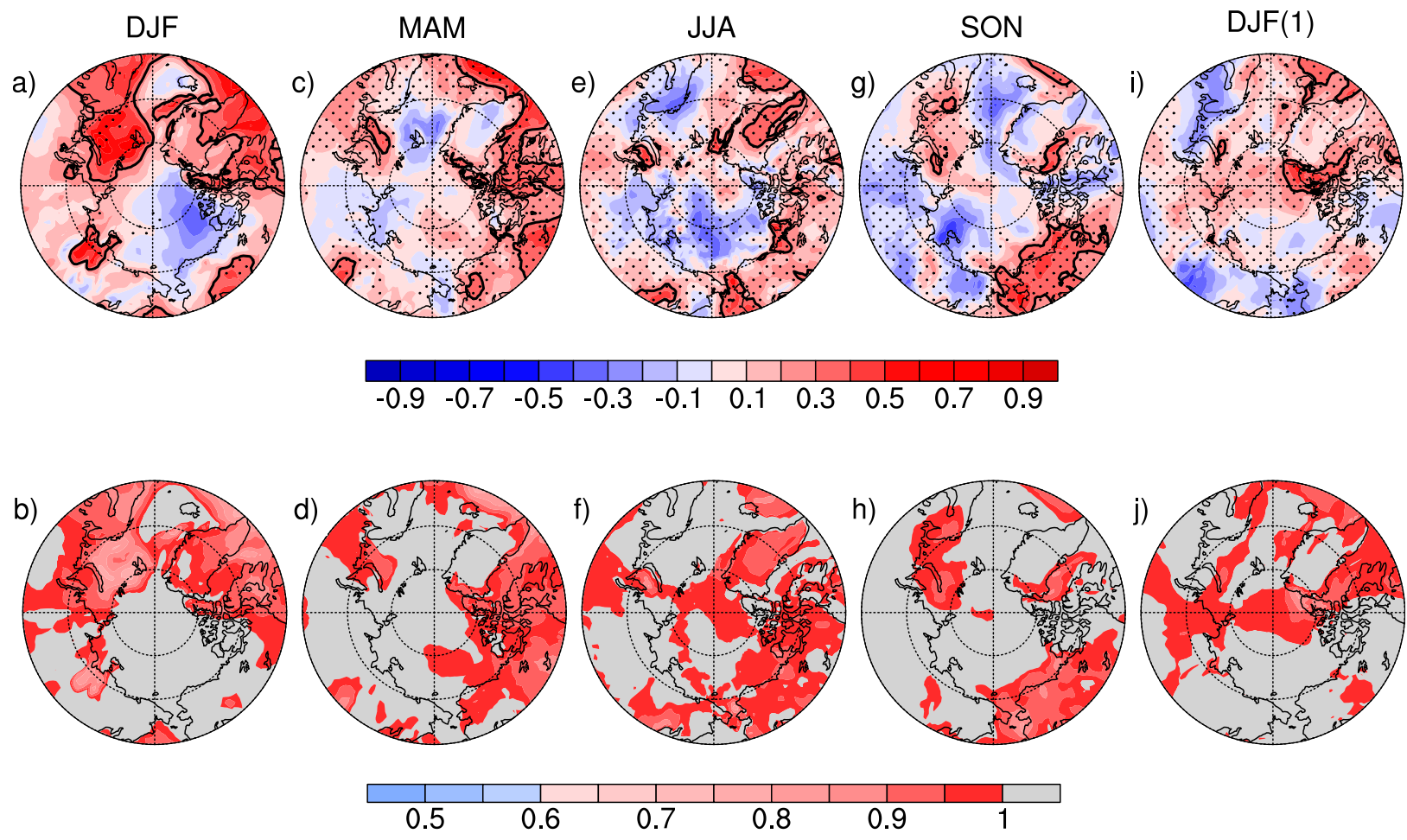

FIG. 12. As in Fig. 6, but for the prediction skills of the detrended 2-m $T$ anomalies. 

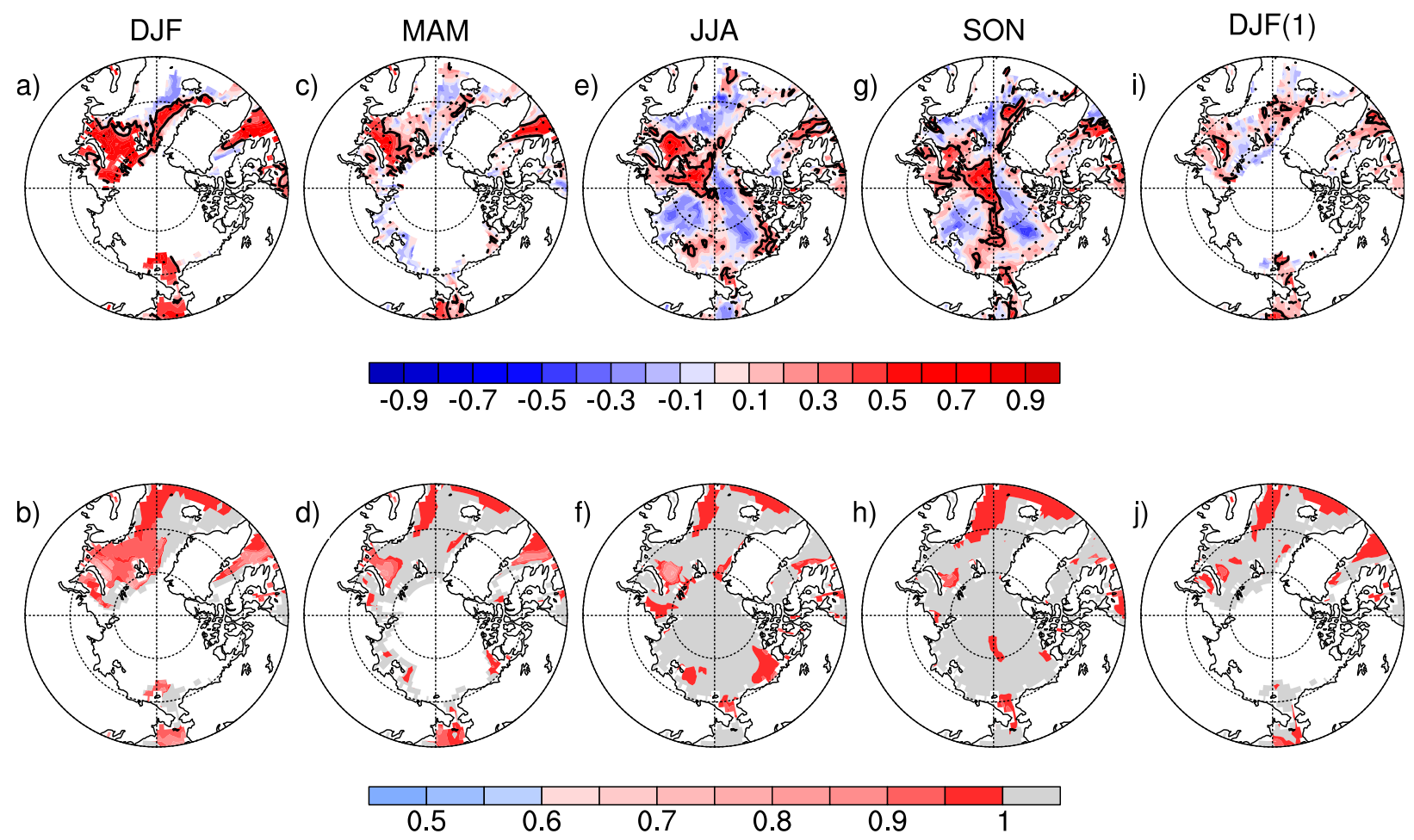

FIG. 13. As in Fig. 7, but for the prediction skills of the detrended SIC anomalies.

same in neutral years. Therefore, the mean of the spatial correlation skills during the neutral years is relatively lower than those during El Niño and La Niña years, which we find to be significant at the $95 \%$ confidence level. Note that high positive spatial correlation skills also exist during some of the neutral years; this suggests that the internal variability of the Arctic winter 2-m $T$ may also be partly driven by other internal processes, which warrants future studies. The spatial pattern correlation skill of the detrended DJF SIC anomalies in the Arctic is higher than that of the detrended 2-m $T$ in most of the years (Fig. 14b), no matter whether ENSO events occur or not. Positive (and even high) pattern correlation skill appears in the neutral years. This indicates that a relatively weak link exists between the detrended SIC over the Arctic in winter and the tropical Pacific ENSO. This may be due to the fact that most parts of the Arctic are covered with sea ice in winter, no matter when El Niño/La Niña years or neutral conditions happen.

Next, we perform composite analysis of the detrended Arctic 2-m $T$ anomalies in El Niño years (1982/83, 1986/87, 1987/88, 1991/92, 1994/95, 1997/98, 2002/03, 2004/05, 2006/07, 2009/10, and 2014/15) and La Niña years (1983/84, 1984/85, 1985/86, 1988/89, 1995/96, 1998/99, 1999/2000, 2000/01, 2005/06, 2007/08, 2008/09, 2010/11, and 2011/12), respectively. We find that there is a clear dipole pattern of the $2-\mathrm{m} T$ anomalies between the east and west of the Arctic region based on the ensemble mean predictions (Figs. 15a,c). During El Niño years, warm anomalies appear in most areas of the Greenland and the northwestern North America, whereas cold anomalies occur over the northern Eurasian continent. A reversed dipole pattern appears in La Niña years with the cold anomalies extending from the Greenland to the Arctic Ocean. Moreover, the regions with prominent warm/cold anomalies are generally coincident with the areas where prediction skill is significant (recall Fig. 12a), particularly over the Barents Sea and the south Greenland. This suggests that the predictability of the internal variability over some regions in the Arctic may originate from tropical Pacific SST anomalies.

To verify whether the composite patterns of the model ensemble mean predictions realistically represent the ENSO's influence on the Arctic in real world, we adopt the NOAA Twentieth Century Reanalysis, version 2 (20CRv2), datasets during 1900-2015 to obtain more ENSO cases. In this way, we select approximately 50 ENSO years to perform the composite analysis for validation. The observed patterns of the Arctic detrended 2-m $T$ anomalies in El Niño and La Niña years (Figs. 15b,d) resemble those of the ensemble mean predictions, except that the composite anomalies in some areas become less statistically significant. This is probably due to the fewer records in the reanalysis (116 years) than in the ensemble predictions ( 35 years for each of the 30 members). In addition, ENSO features during the different periods (1980-2014 vs 1900-2015) may also differ, contributing to the discrepancies between the prediction and reanalysis.

$\mathrm{Li}$ et al. (2019) performed a composite analysis of 30 ENSO events selected during 1960-2017. They found prominent cold 2-m $T$ anomalies over the Barents-Kara Seas only in February during the eastern Pacific El Niño events and warm 2-m $T$ anomalies over northeastern Canada and Greenland during 
a) predictions of Arctic detrended 2-m T(DJF)

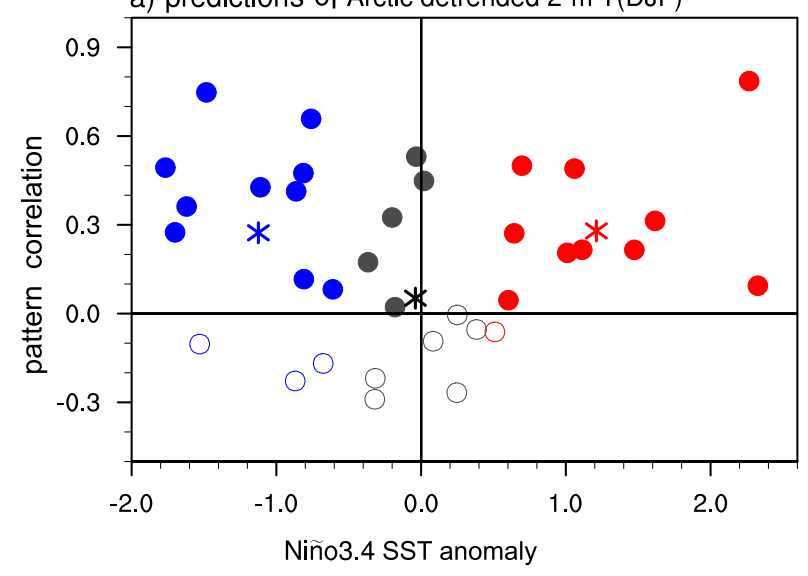

b) predictions of Arctic detrended SIC (DJF)

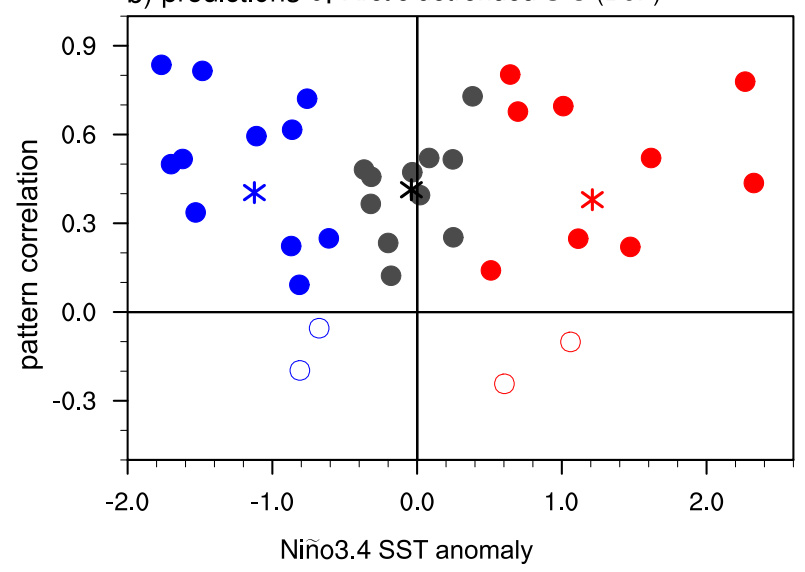

FIG. 14. Scatterplot between the spatial pattern correlation skills of the ensemble mean detrended Arctic (a) 2-m $T$ and (b) SIC anomalies in the first December-February (2-4-months lead) and Niño-3.4 SST index during 1980-2014. The filled and open circles indicate that the pattern correlations are respectively greater than or lower than zero. Red, blue, and black circles indicate El Niño, La Niña, and neutral years, respectively, as based on the NOAA ERSST V5 Niño-3.4 SST index. The averages of correlations in the three ENSO phases are marked with asterisks.

the central Pacific El Niño events (vice versa during La Niña events). In contrast, we find that the dipole pattern during El Niño and La Niña events across the pan-Arctic can extend from boreal winter to the following spring (figures not shown), and regions covered by significant 2-m $T$ anomalies are more widely spread. This disagreement with Li et al. (2019) may be partly due to the larger samples that we adopt to conduct the composite analysis. Nevertheless, our results convincingly demonstrate that DePreSys3 realistically captures the climate response in the Arctic to the interannual tropical Pacific SST signals. The high predictability of the latter contributes to improving the prediction skill of the internal Arctic climate variations.

Following the approach of Acosta Navarro et al. (2020), we have explored the influence of ENSO on the forecast skill of the Arctic 2-m $T$ anomalies in DJF further. Figure 16a shows that the predicted Niño-3.4 index in DJF by DePreSys 3 is highly correlated with NOAA ERSST V5 observations (ACC $=0.95)$. On the basis of this high-skill prediction, we regressed out the ENSO-related signal from the predicted and detrended 2-m $T$ anomalies (Acosta Navarro et al. 2020). Comparison of the ensemble mean forecasts with and without ENSO influence shows that the prediction skill over most areas of the Arctic is slightly enhanced by ENSO, especially in Alaska region (Fig. 16b). This is consistent with the composite analysis (Fig. 15). As was shown in Figs. 14 and 15, the warm and cold phases of ENSO tend to induce an opposite polarity of the spatial distribution of the detrended 2-m $T$ anomalies in the Arctic. ENSO's impact on the Arctic mean 2-m $T$ and its spatial distribution is well predicted in the DePreSys3 (Figs. 10, 14, and 15), although its contribution to the 2-m $T$ prediction at individual grids may not be significant. Future studies are warranted to explore the detailed mechanisms on how ENSO and other possible tropical signals affect the Arctic climate. Note that ENSO's impact on the detrended SIC prediction is small and hence was not investigated in this study.

\section{Summary and discussions}

The Arctic climate has undergone significant changes in recent decades, including the amplified warming and the rapid decrease of sea ice cover. Owing to the increasing impacts of Arctic climate on the vulnerable environment and ecosystems there, accurate seasonal-to-interannual forecast of the Arctic climate becomes more important than before. While the strong multidecadal trends largely contribute to the prediction skill, an operational seasonal-interannual forecast system needs to predict the total anomalies (i.e., the sum of the externally forced and internally driven signals, or the sum of the trends and detrended anomalies). It is the prediction of the total anomalies that many end users require. This study provides a relatively complete document for the assessment of the seasonal-to-interannual prediction skills of 2-m air temperature and sea ice cover over the Arctic, based on an initialized high-resolution coupled model forecast system-the Decadal Prediction System, version 3 (DePreSys3).

Our results show that DePreSys 3 performs well in reproducing both the climatology and variance of the Arctic 2-m T and SIC, albeit regional discrepancies exist in each target season. The ensemble hindcasts with 30 members during 1980-2014 also display statistically significant skills in predicting the Arcticaveraged 2-m temperature and sea ice cover anomalies at lead times of up to 16 months. And the ensemble mean forecasts are generally more skillful than individual member forecasts. Relative to previous studies with statistical methods and low-resolution models, the highresolution DePreSys3 not only displays improved skills at seasonal lead times but also extends the predictions out to interannual lead times, although the predictions of the gridpoint anomalies are less skillful in some areas and target seasons.

We further compared DePreSys3 with the Deutscher Wetterdienst (DWD) 30-member hindcasts and the Japan Meteorological Agency (JMA) 5-member hindcasts, at 1-6-months lead during 1993-2014, provided by the Copernicus Climate Change Service (C3S) Seasonal Forecasts datasets (Fig. 17). The 


\section{DePreSys3}

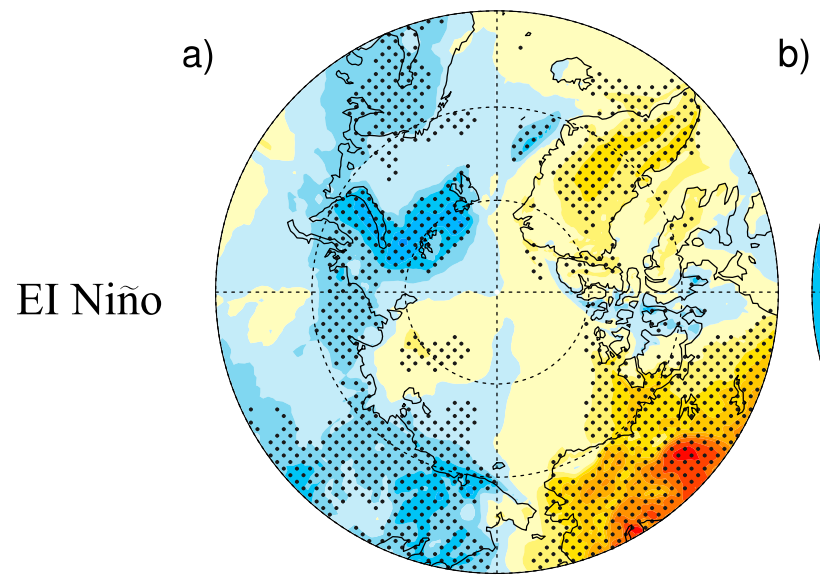

b)

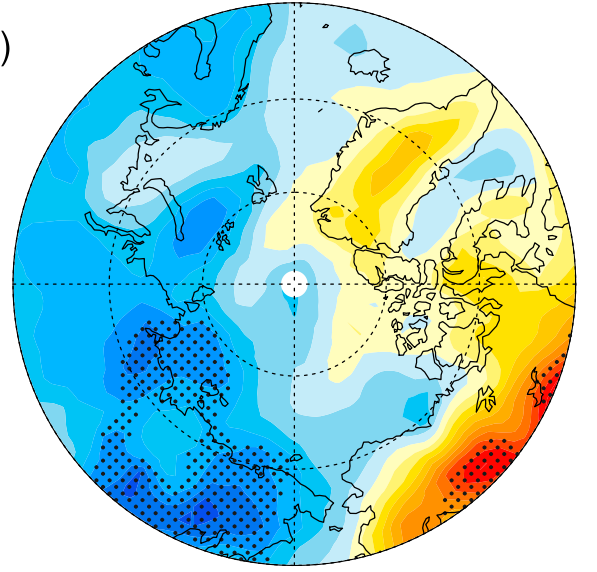

d)

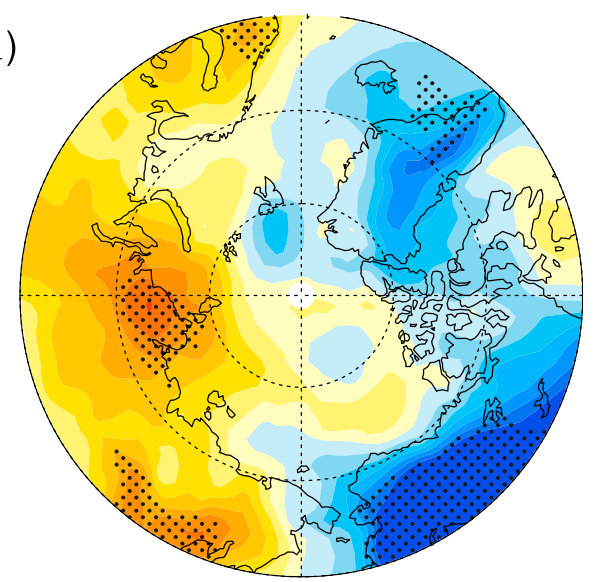

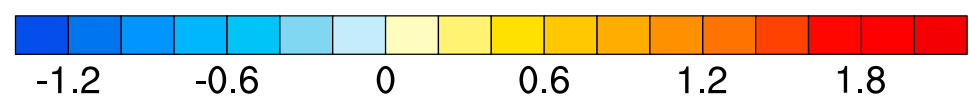

FIG. 15. Spatial distribution of composite detrended 2-m $T$ anomalies in DJF in (a),(b) El Niño years and (c),(d) La Niña years for (left) ensemble mean predictions and (right) reanalysis obtained from 20CRv2 datasets.

two prediction systems have coarser horizontal resolutions than DePreSys3. The DePreSys3 displays higher forecast skills at all of the lead times of 1-6 months except the lower-than-persistence forecast skills at long lead times probably due to the shorter period of hindcasts (cf. Figs. 5 and 17). However, the skill differences are not statistically significant at the $95 \%$ confidence level given the short period of hindcasts and the presence of strong multidecadal trends. To detect true improvements may require the development of a pair of forecast systems in a consistent manner (e.g., the same initialization scheme and ensemble size) but with low and high horizontal resolutions for a longer hindcast period. Nevertheless, the better performance of DePreSys3, relative to the DWD and the JMA as well as other coarse resolution prediction systems mentioned above, indicates the potential benefits of this high-resolution system in predicting the Arctic 2-m $T$ and SIC anomalies.

Consistent with the previous studies, we also find that most predictability of the Arctic climate is attributed to the strong multidecadal trends. In addition, DePreSys3 realistically captures the larger seasonal variations of the 2-m $T$ warming trends and the decreasing trends of the sea ice cover in the Arctic during the 16-month forecast period, albeit the amplitudes of these multidecadal trends are underestimated. Our results show that the seasonally varying Arctic warming trend with the maximum occurring in boreal autumn (SON) lags that of the SIC with the peak reduction rate in early autumn (ASO), consistent with the results of Screen and Simmonds (2010). The trends of the seasonal Arctic SIC tendency (i.e., melting and freezing) and surface net heat flux vary in phase with the seasonal evolution of the 2-m $T$ trend. This suggests a complex interaction between the air and the sea ice over the Arctic Ocean. These relations are well captured by DePreSys 3 during the 16-month forecast period.

However, the predictive skills of the detrended Arctic 2-m $T$ and SIC anomalies are generally low. While statistically significant forecast skill of the detrended SIC anomaly is 


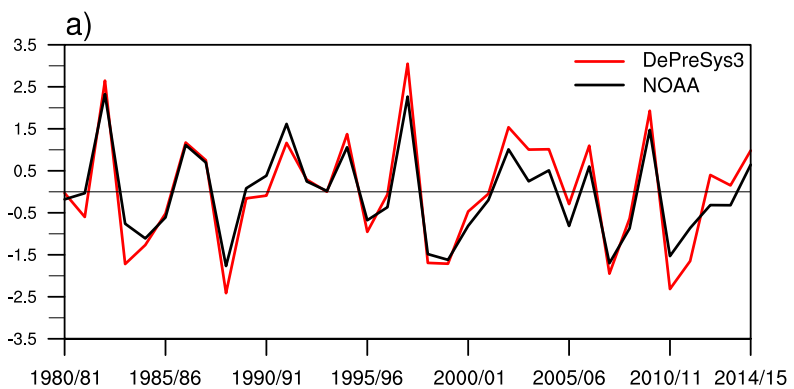

b)
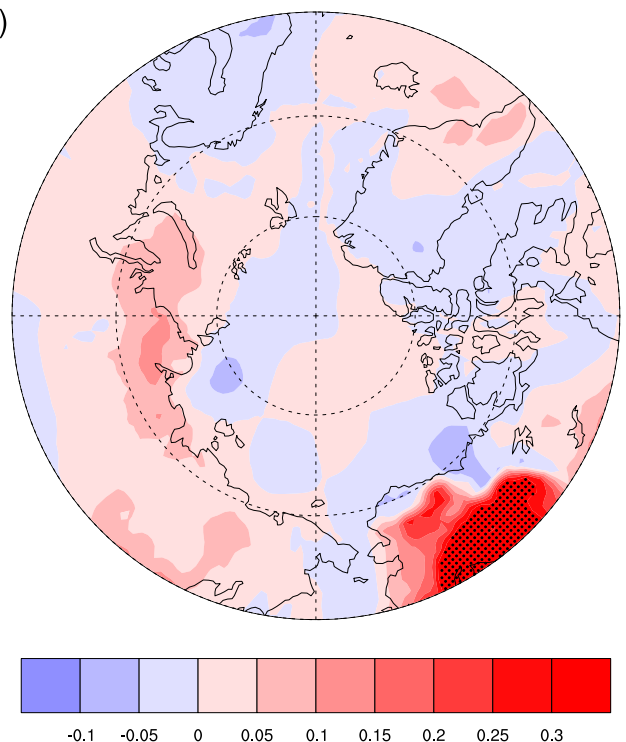

FIG. 16. (a) DJF Niño-3.4 SST anomalies $\left(5^{\circ} \mathrm{S}-5^{\circ} \mathrm{N}, 120^{\circ}-170^{\circ} \mathrm{W}\right)$ as based on NOAA ERSST v5 observations (black line) and ensemble mean predictions initialized from 1 Nov (red line) during 1980-2014. (b) Skill impact (difference in ACC skills between the forecasts with and without ENSO influence) of ENSO on the prediction of DJF detrended 2-m $T$ anomalies. Stippling indicates statistically significant values at the $95 \%$ confidence level.

found at lead times of up to 7 months, prediction of the detrended Arctic 2-m $T$ is only significant at 1-3 months of lead time. Despite the difficulty in predicting the internal variations of the Arctic climate, the short-lead predicted Arctic detrended 2-m $T$ anomalies in boreal winter are close to the reanalysis in El Niño and La Niña years. Our results suggest that ENSO tends to induce a dipole pattern of the detrended 2-m $T$ anomalies between the east and west of the Arctic region. This finding is supported by both the ensemble predictions and the twentieth-century reanalysis and suggests increased Arctic climate predictability in ENSO active years. Consistently, the forecasts with and without ENSO influence also indicate a positive (albeit weak) contribution of ENSO to the detrended 2-m $T$ prediction over most areas of the Arctic. While how ENSO impacts the Arctic climate is not yet clear, the highly predictable tropical sea surface temperature certainly helps improve the predictability of the internal variations of the Arctic climate. Future studies are warranted for a) 2-m T ACC

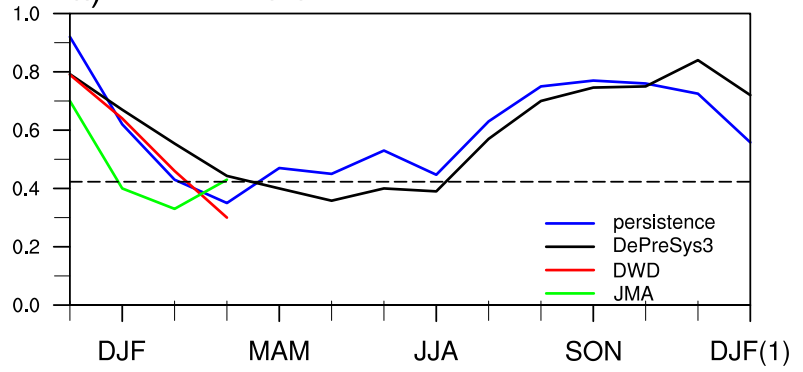

b) SIC ACC

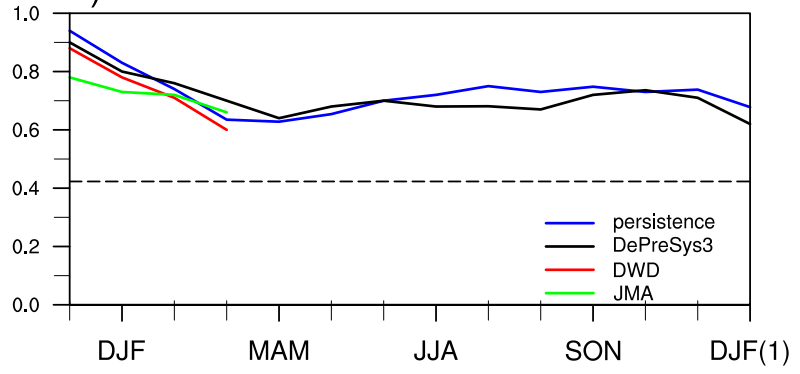

FIG. 17. ACC skills in predicting the seasonal mean Arcticaveraged (a) 2-m $T$ and (b) SIC for each target season during 19932014. The black and red solid lines represent the DePreSys 3 and the DWD ensemble mean ACC skills, respectively, as based on 30member ensemble hindcasts initiated from 1 Nov of every year. The green solid line indicates the JMA 5-member ensemble mean ACC skills, which are initiated from 28 Oct of every year. The horizontal black dashed reference line denotes the statistical significance at the $95 \%$ confidence level. The blue solid line indicates persistence forecast skills.

better understanding the response of the Arctic climate to ENSO and other tropical signals; this is of considerable socioeconomic importance to dealing with the Arctic climate challenges.

Acknowledgments. This work is supported by National Natural Science Foundation of China (Grant 42030605) and National Key R\&D Program of China (Grant 2020YFA0608004). Jiaqing Xue is sponsored by The Startup Foundation for introducing Talent of NUIST (1091011901003). The numerical calculations in this paper have been done on the supercomputing system in the Supercomputing Center of NUIST. We thank three anonymous reviewers for their comments that greatly helped to improve the original paper.

\section{REFERENCES}

Acosta Navarro, J. C., and Coauthors, 2020: Link between autumnal Arctic sea ice and Northern Hemisphere winter forecast skill. Geophys. Res. Lett., 47, e2019GL086753, https:// doi.org/10.1029/2019GL086753.

Barber, D. G., J. V. Lukovich, J. Keogak, S. Baryluk, L. Fortier, and G. H. R. Henry, 2009: The changing climate of the Arctic. Arctic, 61, 7-26, https://doi.org/10.14430/arctic98. 
Best, M. J., and Coauthors, 2011: The Joint UK Land Environment Simulator (JULES), model description-Part 1: Energy and water fluxes. Geosci. Model Dev., 4, 677-699, https://doi.org/ 10.5194/gmd-4-677-2011.

Bintanja, R., and E. C. van der Linden, 2013: The changing seasonal climate in the Arctic. Sci. Rep., 3, 1556, https://doi.org/ 10.1038/srep01556.

Bitz, C. M., M. M. Holland, E. C. Hunke, and R. E. Moritz, 2005: Maintenance of the sea-ice edge. J. Climate, 18, 2903-2921, https://doi.org/10.1175/JCLI3428.1.

Blanchard-Wrigglesworth, E., K. C. Armour, C. M. Bitz, and E. DeWeaver, 2011: Persistence and inherent predictability of Arctic sea ice in a GCM ensemble and observations. J. Climate, 24, 231-250, https://doi.org/10.1175/ 2010JCLI3775.1.

Budikova, D., 2009: Role of Arctic sea ice in global atmospheric circulation: A review. Global Planet. Change, 68, 149-163, https://doi.org/10.1016/j.gloplacha.2009.04.001.

Chapman, W. L., and J. E. Walsh, 2007: Simulations of Arctic temperature and pressure by global coupled models. J. Climate, 20, 609-632, https://doi.org/10.1175/JCLI4026.1.

Chevallier, M., D. Salas y Mélia, A. Voldoire, M. Déqué, and G. Garric, 2013: Seasonal forecasts of the pan-Arctic sea ice extent using a GCM-based seasonal prediction system. J. Climate, 26, 6092-6104, https://doi.org/10.1175/JCLI-D-1200612.1.

Chylek, P., J. Li, M. K. Dubey, M. Wang, and G. Lesins, 2011: Observed and model simulated 20th century Arctic temperature variability: Canadian Earth System Model CanESM2. Atmos. Chem. Phys. Discuss., 11, 22893-22 907, https:// doi.org/10.5194/acpd-11-22893-2011.

Comiso, J. C., and D. K. Hall, 2014: Climate trends in the Arctic as observed from space. Wiley Interdiscip. Rev.: Climate Change, 5, 389-409, https://doi.org/10.1002/wcc.277.

Dai, P., Y. Gao, F. Counillon, Y. Wang, M. Kimmritz, and H. R. Langehaug, 2020: Seasonal to decadal predictions of regional Arctic sea ice by assimilating sea surface temperature in the Norwegian Climate Prediction Model. Climate Dyn., 54, $3863-$ 3878, https://doi.org/10.1007/s00382-020-05196-4.

Day, J. J., S. Tietsche, and E. Hawkins, 2014: Pan-Arctic and regional sea ice predictability: Initialization month dependence. J. Climate, 27, 4371-4390, https://doi.org/10.1175/JCLI-D-1300614.1.

Dee, D. P., and Coauthors, 2011: The ERA-Interim reanalysis: Configuration and performance of the data assimilation system. Quart. J. Roy. Meteor. Soc., 137, 553-597, https://doi.org/ 10.1002/qj.828.

Deser, C., R. Tomas, M. Alexander, and D. Lawrence, 2010: The seasonal atmospheric response to projected Arctic sea ice loss in the late twenty-first century. J. Climate, 23, 333-351, https:// doi.org/10.1175/2009JCLI3053.1.

Ding, Q., J. M. Wallace, D. S. Battisti, E. J. Steig, A. J. Gallant, H. J. Kim, and L. Geng, 2014: Tropical forcing of the recent rapid Arctic warming in northeastern Canada and Greenland. Nature, 509, 209-212, https://doi.org/10.1038/nature13260.

Döscher, R., T. Vihma, and E. Maksimovich, 2014: Recent advances in understanding the Arctic climate system state and change from a Sea ice perspective: A review. Atmos. Chem. Phys., 14, 13 571-13 600, https://doi.org/10.5194/acp-14-135712014.

Drobot, S. D., and J. A. Maslanik, 2002: A practical method for long-range forecasting of ice severity in the Beaufort Sea.
Geophys. Res. Lett., 29, 1213, https://doi.org/10.1029/ 2001 GL014173.

Dunstone, N., D. Smith, A. Scaife, L. Hermanson, R. Eade, and N. Robinson, 2016: Skilful predictions of the winter North Atlantic Oscillation one year ahead. Nat. Geosci., 9, 809-814, https://doi.org/10.1038/ngeo2824.

Eicken, H., 2013: Arctic sea ice needs better forecasts. Nature, 497, 431-433, https://doi.org/10.1038/497431a.

Francis, J. A., and S. J. Vavrus, 2012: Evidence linking Arctic amplification to extreme weather in mid-latitudes. Geophys. Res. Lett., 39, L06801, https://doi.org/10.1029/2012GL051000. , W. Chan, D. J. Leathers, J. R. Miller, and D. E. Veron, 2009: Winter Northern Hemisphere weather patterns remember summer Arctic sea-ice extent. Geophys. Res. Lett., 36, L07503, https://doi.org/10.1029/2009GL037274.

Goosse, H., and Coauthors, 2018: Quantifying climate feedbacks in polar regions. Nat. Commun., 9, 1919, https://doi.org/10.1038/ s41467-018-04173-0.

Guemas, V., and Coauthors, 2016: A review on Arctic sea-ice predictability and prediction on seasonal to decadal timescales. Quart. J. Roy. Meteor. Soc., 142, 546-561, https:// doi.org/10.1002/qj.2401.

Haarsma, R. J., and Coauthors, 2016: High Resolution Model Intercomparison Project (HighResMIP v1.0) for CMIP6. Geosci. Model Dev., 9, 4185-4208, https://doi.org/10.5194/ gmd-9-4185-2016.

Hagedorn, R., F. J. Doblas-Reyes, and T. N. Palmer, 2016: The rationale behind the success of multi-model ensembles in seasonal forecasting-I. Basic concept. Tellus, 57A, 219-233, https://doi.org/10.1111/j.1600-0870.2005.00103.x.

Harnos, K. J., M. L'Heureux, Q. Ding, and Q. Zhang, 2019: Skill of seasonal Arctic sea ice extent predictions using the North American Multimodel Ensemble. J. Climate, 32, 623-638, https://doi.org/10.1175/JCLI-D-17-0766.1.

Holland, M. M., D. A. Bailey, and S. Vavrus, 2010: Inherent sea ice predictability in the rapidly changing Arctic environment of the Community Climate System Model, version 3. Climate Dyn., 36, 1239-1253, https://doi.org/10.1007/s00382-010-0792-4.

Honda, M., J. Inoue, and S. Yamane, 2009: Influence of low Arctic sea-ice minima on anomalously cold Eurasian winters. Geophys. Res. Lett., 36, L08707, https://doi.org/10.1029/ 2008 GL037079.

Hu, C., S. Yang, Q. Wu, Z. Li, J. Chen, K. Deng, T. Zhang, and C. Zhang, 2016: Shifting El Niño inhibits summer Arctic warming and Arctic sea-ice melting over the Canada basin. Nat. Commun., 7, 11721, https://doi.org/10.1038/ncomms11721.

Hunke, E. C., and W. H. Lipscomb, 2010: CICE: The Los Alamos Sea Ice Model documentation and software user's manual. Los Alamos National Laboratory Tech. Rep. LA-CC-06-012, 76 pp., https://csdms.colorado.edu/w/images/CICE_documentation_and_ software_user's_manual.pdf.

IPCC, 2007: Climate Change 2007: The Physical Science Basis. Cambridge University Press, 996 pp.

, 2013: Climate Change 2013: The Physical Science Basis. Cambridge University Press, 1535 pp., https://doi.org/10.1017/ CBO9781107415324.

Jaiser, R., K. Dethloff, D. Handorf, A. Rinke, and J. Cohen, 2012: Planetary- and baroclinic-scale interactions between atmospheric and sea ice cover changes in the Arctic. Tellus, 64A, 11595, https://doi.org/10.3402/tellusa.v64i0.11595.

Johannessen, O. M., and Coauthors, 2004: Arctic climate change: Observed and modelled temperature and sea-ice variability. Tellus, 56A, 328-341, https://doi.org/10.3402/tellusa.v56i4.14418. 
_ S. I. Kuzmina, L. P. Bobylev, and M. W. Miles, 2016: Surface air temperature variability and trends in the Arctic: New amplification assessment and regionalisation. Tellus, 68, 28234, https://doi.org/10.3402/tellusa.v68.28234.

Johnson, C. M., P. Lemke, and T. P. Barnett, 1985: Linear prediction of sea ice anomalies. J. Geophys. Res., 90, 5665-5675, https://doi.org/10.1029/JD090iD03p05665.

Kobayashi, S., and Coauthors, 2015: The JRA-55 reanalysis: General specifications and basic characteristics. J. Meteor. Soc. Japan, 93, 5-48, https://doi.org/10.2151/jmsj.2015-001.

Krahmann, G., and M. Visbeck, 2003: Arctic Ocean sea ice response to northern annular mode-like wind forcing. Geophys. Res. Lett., 30, 1793, https://doi.org/10.1029/2003GL017354.

Kwok, R., 2000: Recent changes in Arctic Ocean sea ice motion associated with the North Atlantic Oscillation. Geophys. Res. Lett., 27, 775-778, https://doi.org/10.1029/1999GL002382.

Lee, S., 2012: Testing of the tropically excited Arctic warming mechanism (TEAM) with traditional El Niño and La Niña. J. Climate, 25, 4015-4022, https://doi.org/10.1175/JCLI-D-1200055.1.

—- T. Gong, N. Johnson, S. B. Feldstein, and D. Pollard, 2011: On the possible link between tropical convection and the Northern Hemisphere Arctic surface air temperature change between 1958 and 2001. J. Climate, 24, 4350-4367, https:// doi.org/10.1175/2011JCLI4003.1.

Li, Z., W. Zhang, M. F. Stuecker, H. Xu, F.-F. Jin, and C. Liu, 2019: Different effects of two ENSO types in Arctic surface temperature in boreal winter. J. Climate, 32, 4943-4961, https:// doi.org/10.1175/JCLI-D-18-0761.1.

Lindsay, R. W., J. Zhang, A. J. Schweiger, and M. A. Steele, 2008: Seasonal predictions of ice extent in the Arctic Ocean. J. Geophys. Res., 113, C02023, https://doi.org/10.1029/2007JC004259.

MacLachlan, C., and Coauthors, 2015: Global Seasonal forecast system version 5 (GloSea5): A high-resolution seasonal forecast system. Quart. J. Roy. Meteor. Soc., 141, 1072-1084, https://doi.org/10.1002/qj.2396.

Madec, G., B. Rachid, B. Clément, C. Andrew, D. Srdan, F. Rachel, and O. Paolo, 2013: NEMO ocean engine, version 3.4. IPSL Note du Pole de Modélisation 27, 333 pp.

Megann, A., and Coauthors, 2014: GO5.0: The joint NERC-Met Office NEMO global ocean model for use in coupled and forced applications. Geosci. Model Dev., 7, 1069-1092, https:// doi.org/10.5194/gmd-7-1069-2014.

Merryfield, W. J., W.-S. Lee, W. Wang, M. Chen, and A. Kumar, 2013: Multi-system seasonal predictions of Arctic sea ice. Geophys. Res. Lett., 40, 1551-1556, https://doi.org/10.1002/ grl.50317.

Mysak, L. A., and S. A. Venegas, 1998: Decadal climate oscillations in the Arctic: A new feedback loop for atmosphere-ice-ocean interactions. Geophys. Res. Lett., 25, 3607-3610, https:// doi.org/10.1029/98GL02782.

Notz, D., and J. Marotzke, 2012: Observations reveal external driver for Arctic sea-ice retreat. Geophys. Res. Lett., 39, L08502, https://doi.org/10.1029/2012GL051094.

Overland, J. E., and M. Wang, 2010: Large-scale atmospheric circulation changes are associated with the recent loss of Arctic sea ice. Tellus, 62A, 1-9, https://doi.org/10.1111/ j.1600-0870.2009.00421.x.

Palmer, T. N., and Coauthors, 2004: Development of a European Multimodel Ensemble System for Seasonal to Interannual Prediction (DEMETER). Bull. Amer. Meteor. Soc., 85, 853872, https://doi.org/10.1175/BAMS-85-6-853.
Petoukhov, V., and V. A. Semenov, 2010: A link between reduced Barents-Kara sea ice and cold winter extremes over northern continents. J. Geophys. Res., 115, D21111, https://doi.org/ 10.1029/2009JD013568.

Pithan, F., and T. Mauritsen, 2014: Arctic amplification dominated by temperature feedbacks in contemporary climate models. Nat. Geosci., 7, 181-184, https://doi.org/10.1038/ngeo2071.

Rae, J. G. L., H. T. Hewitt, A. J. Keen, J. K. Ridley, A. E. West, C. M. Harris, E. C. Hunke, and D. N. Walters, 2015: Development of the Global Sea Ice 6.0 CICE configuration for the Met Office Global Coupled model. Geosci. Model Dev., 8 , 2221-2230, https://doi.org/10.5194/gmd-8-2221-2015.

Rayner, N. A., D. E. Parker, E. B. Horton, C. K. Folland, L. V. Alexander, D. P. Rowell, E. C. Kent, and A. Kaplan, 2003: Global analyses of sea surface temperature, sea ice, and night marine air temperature since the late nineteenth century. J. Geophys. Res., 108, 4407, https://doi.org/10.1029/2002JD002670.

Rigor, I. G., J. M. Wallace, and R. L. Colony, 2002: Response of sea ice to the Arctic oscillation. J. Climate, 15, 2648-2663, https://doi.org/ 10.1175/1520-0442(2002)015<2648:ROSITT >2.0.CO;2.

Sassi, F., D. Kinnison, B. A. Boville, R. R. Garcia, and R. Roble, 2004: Effect of El Niño-Southern Oscillation on the dynamical, thermal, and chemical structure of the middle atmosphere. J. Geophys. Res., 109, D17108, https://doi.org/10.1029/2003JD004434.

Screen, J. A., and I. Simmonds, 2010: Increasing fall-winter energy loss from the Arctic Ocean and its role in Arctic temperature amplification. Geophys. Res. Lett., 37, L16707, https://doi.org/ 10.1029/2010GL044136.

,,-- C. Deser, and R. Tomas, 2013: The atmospheric response to three decades of observed Arctic sea ice loss. J. Climate, 26, 1230-1248, https://doi.org/10.1175/JCLI-D-12-00063.1.

Serreze, M. C., and J. A. Francis, 2006: The Arctic amplification debate. Climatic Change, 76, 241-264, https://doi.org/10.1007/ s10584-005-9017-y.

— plification: A research synthesis. Global Planet. Change, 77, 85-96, https://doi.org/10.1016/j.gloplacha.2011.03.004.

_- and J. Stroeve, 2015: Arctic sea ice trends, variability and implications for seasonal ice forecasting. Philos. Trans. Roy. Soc. London, 373A, 20140159, https://doi.org/10.1098/rsta.2014.0159. _ A. P. Barrett, J. C. Stroeve, D. N. Kindig, and M. M. Holland, 2009: The emergence of surface-based Arctic amplification. Cryosphere, 3, 11-19, https://doi.org/10.5194/tc-3-11-2009.

Sigmond, M., J. C. Fyfe, G. M. Flato, V. V. Kharin, and W. J. Merryfield, 2013: Seasonal forecast skill of Arctic sea ice area in a dynamical forecast system. Geophys. Res. Lett., 40, 529534, https://doi.org/10.1002/grl.50129.

Smith, D. M., and J. M. Murphy, 2007: An objective ocean temperature and salinity analysis using covariances from a global climate model. J. Geophys. Res., 112, C02022, https://doi.org/ 10.1029/2005JC003172.

Valcke, S., 2013: The OASIS3 coupler: A European climate modelling community software. Geosci. Model Dev., 6, 373388, https://doi.org/10.5194/gmd-6-373-2013.

Walsh, J. E., 1980: Empirical orthogonal function and the statistical predictability of sea ice extent. Sea Ice Processes and Models, R. S. Pritchard, Ed., University of Washington Press, 373-384. , 1983: The role of sea ice in climatic variability: Theories and evidence. Atmos.-Ocean, 21, 229-242, https://doi.org/10.1080/ 07055900.1983 .9649166$.

Walters, D. N., and Coauthors, 2017: The Met Office Unified Model Global Atmosphere 6.0/6.1 and JULES Global Land 
6.0/6.1 configurations. Geosci. Model Dev., 10, 1487-1520, https://doi.org/10.5194/gmd-10-1487-2017.

Wang, W., M. Chen, and A. Kumar, 2013: Seasonal prediction of Arctic sea ice extent from a coupled dynamical forecast system. Mon. Wea. Rev., 141, 1375-1394, https://doi.org/10.1175/ MWR-D-12-00057.1.

Williams, K. D., and Coauthors, 2015: The Met Office Global Coupled model 2.0 (GC2) configuration. Geosci. Model Dev., 8, 1509-1524, https://doi.org/10.5194/gmd-8-1509-2015.

Wood, N., and Coauthors, 2014: An inherently massconserving semi-implicit semi-Lagrangian discretization of the deep-atmosphere global nonhydrostatic equations.
Quart. J. Roy. Meteor. Soc., 140, 1505-1520, https:// doi.org/10.1002/qj.2235.

Yoo, C., S. Feldstein, and S. Lee, 2011: The impact of the Madden-Julian oscillation trend on the Arctic amplification of surface air temperature during the 1979-2008 boreal winter. Geophys. Res. Lett., 38, L24804, https://doi.org/ 10.1029/2011GL049881.

Zhang, J., M. Steele, D. A. Rothrock, and R. W. Lindsay, 2004: Increasing exchanges of Greenland-Scotland ridge and their links with the North Atlantic Oscillation and Arctic sea ice. Geophys. Res. Lett., 31, L09307, https://doi.org/ 10.1029/2003GL019304. 